\title{
A sensitivity study of radiative fluxes at the top of atmosphere to cloud-microphysics and aerosol parameters in the community atmosphere model CAM5
}

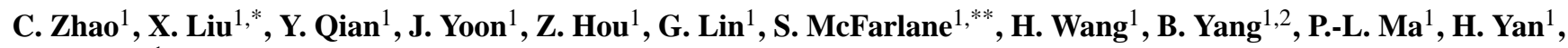 \\ and J. Bao ${ }^{1}$ \\ ${ }^{1}$ Pacific Northwest National Laboratory, Richland, WA, USA \\ ${ }^{2}$ School of Atmospheric Sciences, Nanjing University, Nanjing, China \\ * now at: Department of Atmospheric Science, University of Wyoming, Laramie, WY, USA \\ ** now at: US Department of Energy, Washington, DC, USA
}

Correspondence to: C. Zhao (chun.zhao@pnnl.gov)

Received: 11 April 2013 - Published in Atmos. Chem. Phys. Discuss.: 8 May 2013

Revised: 25 September 2013 - Accepted: 7 October 2013 - Published: 8 November 2013

\begin{abstract}
In this study, we investigated the sensitivity of net radiative fluxes (FNET) at the top of atmosphere (TOA) to 16 selected uncertain parameters mainly related to the cloud microphysics and aerosol schemes in the Community Atmosphere Model version 5 (CAM5). We adopted a quasiMonte Carlo (QMC) sampling approach to effectively explore the high-dimensional parameter space. The output response variables (e.g., FNET) are simulated using CAM5 for each parameter set, and then evaluated using the generalized linear model analysis. In response to the perturbations of these 16 parameters, the CAM5-simulated global annual mean FNET ranges from -9.8 to $3.5 \mathrm{~W} \mathrm{~m}^{-2}$ compared to $1.9 \mathrm{~W} \mathrm{~m}^{-2}$ with the default parameter values. Variance-based sensitivity analysis is conducted to show the relative contributions of individual parameter perturbations to the global FNET variance. The results indicate that the changes in the global mean FNET are dominated by changes in net cloud forcing $(\mathrm{CF})$ within the parameter ranges being investigated. The threshold size parameter related to auto-conversion of cloud ice to snow is identified as one of the most influential parameters for FNET in CAM5 simulations. The strong heterogeneous geographic distribution of FNET variance shows that parameters have a clear localized effect over regions where they are acting. However, some parameters also have non-local impacts on FNET variance. Although external factors, such as perturbations of anthropogenic and natural emissions, largely affect FNET variance at the regional
\end{abstract}

scale, their impact is weaker than that of model internal parameters in terms of simulating global mean FNET. The interactions among the 16 selected parameters contribute a relatively small portion to the total FNET variance over most regions of the globe. This study helps us better understand the parameter uncertainties in the CAM5 model, and thus provides information for further calibrating uncertain model parameters with the largest sensitivity.

\section{Introduction}

Radiative flux (FNET) at the top of atmosphere (TOA) is important to the earth climate system and drives surface temperature change (Forster et al., 2007). Changes of earth system components, such as greenhouse gases, aerosols, clouds, and land surface properties, can alter the FNET (Anderson et al., 2010, 2012). These changes are normally expressed in terms of radiative forcing, an index measuring the alteration of incoming and outgoing energy in the earth climate system due to a given factor as a potential climate change mechanism. Due to the complexity of the earth atmosphere system, the quantification of radiative forcing has proven difficult and is limited by uncertainties (Forster et al., 2007). For example, the fourth assessment report of the Intergovernmental Panel on Climate Change (IPCC AR4) documented a total anthropogenic radiative forcing of $1.6 \mathrm{~W} \mathrm{~m}^{-2}$ with an uncertainty 
range of $0.6-2.4 \mathrm{~W} \mathrm{~m}^{-2}$. Quantifying and reducing the uncertainties of radiative forcing in earth system components is necessary to improve the projection of future climate change (Kiehl, 2007).

Clouds and aerosols are two of the most important agents in the climate system influencing the earth energy balance. Understanding of the roles of clouds and aerosols in the climate system has been significantly improved, but they remain two of the dominant sources of uncertainty in climate models (Schwartz, 2004; Collins et al., 2006; Lohmann et al., 2007; Ramanathan and Carmichael, 2008; Lohmann and Ferrachat, 2010; Lee et al., 2012). Clouds affect the climate system by modifying radiation fluxes through the atmosphere (Loeb et al., 2009). Aerosols interact with solar radiation through absorption and scattering and to a lesser extent with terrestrial radiation (Forster et al., 2007). Aerosols can also serve as cloud condensation nuclei (CCN) and/or ice nuclei (IN) to influence cloud albedo and lifetime (e.g., Lohmann and Feitcher, 2005). Many cloud and aerosol processes are complicated, and cloud and aerosol amounts and properties are extremely heterogeneous (e.g., Zhao et al., 2013). To date, global climate models cannot fully treat details of the physical processes governing cloud and aerosol formation, lifetime, and radiative effects due to insufficient physical understanding or relatively coarse spatial resolution (due to computational limitation) that cannot resolve cloud dynamics. Therefore, global climate models represent these processes using simplified parameterizations that typically include empirical parameters with large uncertainties. Moreover, the parameterizations normally vary significantly from one model to another (Boucher and Lohmann, 1995; Penner et al., 2006; Ghan and Easter, 2006; Bauer et al., 2008; Fast et al., 2011). In addition to internal model parameters related to physical and chemical processes, aerosol radiative forcing is also sensitive to external factors such as emissions (Dentener et al., 2006; Textor et al., 2006). IPCC AR4 reported the estimated aerosol radiative forcing (including both direct and first indirect effects) with a wide uncertainty range from -1.8 to $-0.1 \mathrm{~W} \mathrm{~m}^{-2}$. This uncertainty is mainly due to structural (model-to-model) differences and uncertainties in aerosols.

In the past two decades, most efforts to define model uncertainty of radiative forcing have focused on multi-model inter-comparisons (e.g., Penner et al., 2006; Textor et al., 2006; Quaas et al., 2009). Although this approach provides useful information about model diversity, it limits the estimation of the parametric sensitivity in the individual models (Jackson et al., 2004, 2008; Haerter et al., 2009; Lohmann and Ferrachat, 2010). In this study, we focus on evaluating the parametric sensitivity related to cloud microphysics and aerosol processes and emissions of an individual model, the Community Atmosphere Model version 5 (CAM5). CAM5 is a community model (Neale et al., 2010) and has been used to estimate radiative forcing of aerosols and their impact on the climate system (e.g., Ghan et al., 2012; Liu et al., 2012; Gettelman et al., 2012; Hurrell et al., 2013). As CAM5 is an im- portant component of the Community Earth System Model (CESM), quantifying the sensitivity of simulated FNET in CAM5 to parametric and emission perturbations will improve our understanding of uncertainty in CESM.

Sensitivity analysis (SA) can quantify model parametric sensitivity and identify the processes that make the largest contribution to it. The most widely used SA approach is to conduct "one-at-a-time" (OAT) sensitivity tests that systematically investigate departures of model behavior from the baseline simulation by varying one parameter at a time (e.g., Gao et al., 1996; Lohmann and Ferrachat, 2010; Li et al., 2011). Lohmann and Ferrachat (2010) used the OTA SA method to investigate the impact of important tunable parameters associated with ice-cloud optical properties and convective and stratiform clouds on the present-day climate and aerosol effect in a global climate model. They concluded that tuning of these parameters has a negligible influence on the anthropogenic aerosol effect. However, OAT tests can only test a limited number of parameters at the same time and consider only a small fraction of the total parameter uncertainty space. They also cannot take parameter interactions into account (Saltelli and Annonia, 2010). The OAT approach has been criticized for its failure to explore the full parameter space for highly nonlinear models (e.g., Bastidas et al., 2006; Rosero et al., 2010; Lee et al., 2012).

A more comprehensive approach is to populate the statistical distribution of model outputs by sampling hundreds or thousands of possible values for each parameter. The SA, such as analysis of variance and variance decomposition, then uses the output distributions to understand the contribution of each parameter to the overall variance. Lee et al. (2012) used the Latin hypercube sampling (LHS) method and applied a Gaussian process emulation technique in a global chemical transport model to explore the parameter space and quantify uncertainty in simulating CCN concentrations. They concluded that $\mathrm{CCN}$ concentrations in model simulations are sensitive only to emission parameters in polluted regions but to uncertainties in parameters associated with model processes in all other regions. In a follow-up study, Lee et al. (2013) extended the previous work to examine 28 uncertain model parameters to more fully assess the magnitude and causes of uncertainty in modeling CCN.

To date, there has been no such comprehensive SA study on CAM5 parameters related to cloud microphysics and aerosol to our knowledge. From the limited number of studies performed to date, it is not clear which parameters associated with cloud microphysics parameterizations, aerosol parameterizations, aerosol emissions, or precursor emissions are most responsible for the uncertainty in the CAM5simulated climate variables. In this study, we adopt an SA framework that integrates an exploratory sampling approach (quasi-Monte Carlo) and a generalized linear model analysis, in order to evaluate the sensitivity of simulated FNET to cloud microphysics and aerosol parameters. This paper is organized as follows. Sections 2 and 3 provide details of the 
CAM5 model configuration and the SA methodology used in this study. The SA of the CAM5-simulated FNET associated with cloud microphysics and aerosol parameters is presented in Sect. 4. The findings are summarized and discussed in Sect. 5.

\section{Methodology}

\subsection{Model description}

The model used in this study is CAM5 (release v5.1.02). Details on CAM5 can be found in Neale et al. (2010); here we briefly describe the key aerosol and cloud parameterizations that are relevant to this study. The treatment of aerosols in CAM5 is described in detail in Liu et al. (2012). The threemode version of the modal aerosol scheme (MAM3) used in this study features Aitken, accumulation, and coarse modes. Aerosol components are internally mixed in each mode and the mass and number concentrations in each mode are updated during the simulation. The size distribution of each mode is assumed to be log-normal and the width $(\sigma)$ of the log-normal distribution is prescribed. Fifteen aerosol species are transported. The model includes important processes that influence the aerosol life cycle such as emission, dry and wet deposition, gas- and aqueous-phase chemistry, nucleation, coagulation, and condensational growth. The performance of MAM3 aerosol module in year 2000 simulations of CAM5 has been evaluated by Liu et al. (2012).

The CAM5 model treats physical processes in stratiform and cumulus clouds in separate parameterizations. Stratiform cloud macrophysics is described by Gettelman et al. (2010). In the stratiform cloud microphysics parameterization, mass and number concentrations of cloud droplets and ice crystals are predicted, while those of rain and snow are diagnosed (Morrison and Gettelman, 2008; Gettelman et al., 2008, 2010). Aerosol influence on stratiform cloud microphysics is based on Abdul-Razzak and Ghan (2000) for the droplet activation and on Liu et al. (2007) for ice nucleation. Shallow cumulus clouds are treated as described in Park and Bretherton (2009) while deep convective clouds are parameterized following Zhang and McFarlane (1995) with the modifications of Neale et al. (2008). In the version of CAM5 used in this study, aerosol cannot directly affect cumulus cloud microphysics but can be scavenged by convective clouds.

The Rapid Radiative Transfer Model for GCMs (RRTMG) is used for long-wave and shortwave radiative transfer (Mlawer et al., 1997; Iacono et al., 2000). Aerosol optical properties are calculated following Ghan and Zaveri (2007). The optical properties of aerosols and clouds (OPAC) data set (Hess et al., 1998) is used for refractive indices for most aerosol components, but the value $(1.95+0.79 i)$ from Bond and Bergstrom (2006) is used for black carbon (BC). The liquid and ice-cloud optical properties are calculated follow- ing Morrison and Gettelman (2008) and Mitchell (2000 and 2006), respectively.

\subsection{Experiment design}

In this study, we use $1.9^{\circ}$ latitude $\times 2.5^{\circ}$ longitude resolution with 30 vertical layers. Each simulation is performed with the Atmosphere Model Intercomparison Program (AMIP) configuration that uses prescribed greenhouse gas concentrations and sea surface temperature (SST) for the years from 2000 to 2004. Emissions are from the IPCC AR5 estimates (Lamarque et al., 2010). Simulations are run for 2000-2004. The average of the final four years (2001-2004) of the simulation is considered as one sample experiment. A total of $256 \mathrm{ex}-$ periments are conducted, as described in Sect. 2.3.2, and the statistical analysis is based on these 256 experiments.

\subsection{SA framework}

\subsubsection{Parameterization}

While many parameters likely contribute to uncertainties in CAM5, this study focuses on 16 parameters related to cloud microphysical processes and aerosol physics and chemistry processes including cloud ice microphysics, cloud droplet activation, aerosol wet scavenging, solar radiation absorption by dust, and emission fluxes and size distributions (see the descriptions shown in Table 1). These 16 uncertain parameters were identified by model developers of CAM5 and also agree with previous studies (R. C. Easter, S. J. Ghan, and H. Morrison, personal communication, 2012). For example, the ice falling speed (ai) has been identified as the second most influential parameter to the climate sensitivity (Sanderson et al., 2008) and has a significant effect on cloud radiative forcing (Mitchell et al., 2008). The parameter for auto-conversion of cloud ice to snow (des) is one of the most effective tuning parameters in CAM5 for the radiative budgets. Both subgrid in-cloud vertical velocity (wsubmin) (Golaz et al., 2011) and cloud droplet number lower limiter (cdnl) (Hoose et al., 2009) both play crucial roles on cloud droplet number concentration and aerosol indirect effect. Tuning parameters that control wet removal of aerosols (sol_facti and sol_factic) remains a key source of uncertainty in global aerosol models, which strongly affects the vertical distribution and long-range transport of submicron aerosols (Vignati et al., 2010; Wang et al., 2013). Dust absorption property (refindex_dust_sw) is a key quantity with large uncertainty for aerosol optical properties (Zhao et al., 2011). There are large uncertainties in the emissions of sea-salt and mineral dust (emis_SEAS and emis_DUST) (Textor et al., 2006), as well as secondary organic aerosol (SOA) formation (emis_SOAg) (e.g., Spracklen et al., 2011) in global aerosol models. In addition, we perturb the emission rate of anthropogenic $\mathrm{SO}_{2}$ (emis_SO $\mathrm{SO}_{2}$ ) and the molar fraction of it directly emitted as sulfate (emis_SO4f), as well as 
the emission rate of anthropogenic carbonaceous aerosols (emis_POM and emis_EC) and the emission size of aerosols in accumulation mode controlled by the number concentration (emis_num_a1_surf). Other parameters may also be important for radiative fluxes but they are generally less uncertain and so are not examined here.

These 16 parameters include both perturbations in internal parametric variability (parameters shown in blue in Table 1) and perturbations in emission scenarios (parameters shown in red in Table 1). The perturbation ranges (from minimum to maximum) of these 16 parameters (shown in Table 1) reflect our best knowledge of parameter uncertainties in aerosol (R. C. Easter and S. J. Ghan, personal communication, 2012) and cloud microphysics parameterizations (H. Morrison, personal communication, 2012) in CAM5.

\subsubsection{Quasi-Monte Carlo sampling}

In this study, the probability distribution of each model parameter is assumed to be uniform within its uncertainty range (from minimum to maximum). Due to the high dimensionality of the parameter space and computational demand, efficient and reliable SAs must be used to explore the parameter space. Systematic sampling techniques, such as Simpson's rule, are insufficient (Tarantola, 2005). Traditional Monte Carlo (MC) sampling is also insufficient as it produces many gaps and clumps, which may result in missing and/or duplicated numerical simulations. A quasi-Monte Carlo (QMC) sampling approach guarantees good dispersion between samples (Caflisch, 1998) and therefore is adopted in this study. QMC sampling can achieve good uniformity even in higherdimensional projections by filling gaps and avoiding clumps in the sampling points, achieving better performance than MC and LHS in general (Wang and Sloan, 2008; Hou et al., 2012). QMC sampling produces a series of samples with controlled deterministic inputs instead of random ones.

The number of QMC samples is normally a power of 2 and is usually chosen as a trade-off between computational time and numerical error. It is important to make sure there is no significant under-sampling issue that may affect the reliability of the developed relationships between the output responses (e.g., FNET) and the independent variables (see Table 1). Therefore, tests were performed to determine the number of QMC samples (up to 256 samples) needed for reliable outputs. Based on the tests, we have confirmed that output statistics and sensitivity based on 128 samples are comparable to those based on 256 samples (not shown). In this study, the analysis results from 256 samples are used.

\subsubsection{Statistical analysis}

After CAM5 simulations are completed for each combined parameter set, we perform statistical analyses of the output responses (e.g., the variance of FNET) to these internal and external parameters, including their linear/nonlinear and interaction effects. There are various sensitivity evaluation techniques, for example, multivariate adaptive regression splines (MARS), generalized linear model (GLM), Morris method, and Sobol' method. They can be used to separate the main, interaction, and high-order effects of input parameters (Friedman, 1991; Morris, 1991; Sobol', 1993). Among these methods, GLM method and Sobol' method can provide quantitate measures of parameter sensitivity in terms of output variances that can be explained/fitted by the linear, interaction, and high-order terms of input variables and integrated with parameter reduction/selection techniques if necessary. The GLM method is used for sensitivity analysis in this study. The GLM performs statistical tests of the significance of the input parameters. These statistical significance values are used to rank the contributions of inputs to the overall variability of each output response through a full, variance-based SA. The SA quantifies the variance of the simulated FNET that results from the perturbations of selected model parameters and identifies the significant parameters for FNET variance in global or specific regions. The GLM assumes polynomial relationships between the output (e.g., FNET) variance and input parameter variations with linear, quadratic, and interaction terms in sensitivity analyses to facilitate testing of the significance of the corresponding linear-quadratic interaction effects. The polynomial assumption is inappropriate if the fitted variance is too small (i.e., coefficients of determination $\left(R^{2}\right)$ is close to 0 ).

A GLM is fitted with the following starting model:

$Y^{i}=\beta_{0}+\sum_{j=1}^{n} \beta_{j} \cdot p_{j}^{i}+\sum_{j=1}^{n} \sum_{k=1}^{n} \beta_{j, k} \cdot p_{j}^{i} \cdot p_{k}^{i}+\varepsilon_{i}, \varepsilon_{i} \stackrel{i i d}{\sim} N\left(0, \sigma^{2}\right)$,

where $p_{j}^{i}$ represents the $i$-th realization of the $j$-th parameter; $Y_{i}$ represents the $i$-th response variable (e.g., FNET); $\beta_{j}$ and $\beta_{j, k}$ represent the coefficients of linear and two-way interaction terms, respectively; $\varepsilon_{i}$ denotes the residual for the $i$-th realization; $n$ is the number of input parameters/factors, and $N$ denotes the normal/Gaussian distribution with mean and variance in the parenthesis. This model assumes the response variable is a combination of these aforementioned parameters, and the model-fitting residuals $\varepsilon_{i}$ follow independent normal distributions with zero mean and unit variance.

The GLM evaluates the statistical significance of the input parameters through null hypothesis tests, which proposes that no statistical significance exists in a set of given observations The $t$ statistic value for testing the null hypothesis that the regression coefficients $\hat{\beta}_{i}$ are zero (such that the corresponding parameter is likely insignificant) is given by $t=\hat{\beta}_{i} / \operatorname{SE}\left(\hat{\beta}_{i}\right)$. The $P$ value for the test and interpreted variance (fitted sum squares) by each term also are computed. The coefficient of determination $\left(R^{2}\right)$ of model fitness also is computed as the fitted variance relative to the overall variance of each output response. A parameter is considered to be significant if the corresponding $P$ value is smaller than a chosen significance level of the test (e.g., 0.05 or 0.1) (McCullagh and Nelder, 
Table 1. CAM5 cloud microphysics and aerosol parameters of interest. The top eight parameters are defined as internal parameters and the rest are defined as external parameters.

\begin{tabular}{llll}
\hline Tuning parameter & Description & Default value & Investigated range \\
\hline ai & Fall-speed parameter for cloud ice & $700\left(\mathrm{~s}^{-1}\right)$ & $350-1400\left(\mathrm{~s}^{-1}\right)$ \\
as & Fall-speed parameter for snow & $11.72\left(\mathrm{~m}^{0.59} \mathrm{~s}^{-1}\right)$ & $5.86-23.44\left(\mathrm{~m}^{0.59} \mathrm{~s}^{-1}\right)$ \\
cdnl & Cloud droplet number limiter & $0.0\left(\# \mathrm{~m}^{-3}\right)$ & $0-1 . \mathrm{e} 7\left(\# \mathrm{~m}^{-3}\right)$ \\
dcs & Auto-conversion size threshold for ice to snow & $400(\mu \mathrm{m})$ & $100-500(\mu \mathrm{m})$ \\
wsubmin & Minimum sub-grid vertical velocity for cloud droplet activation & $0.2\left(\mathrm{~m} \mathrm{~s} \mathrm{~s}^{-1}\right)$ & $0-1\left(\mathrm{~m} \mathrm{~s} \mathrm{~s}^{-1}\right)$ \\
sol_facti & Solubility factor for cloud-borne aerosols in stratiform clouds & 1 (fraction) & $0.5-1$ (fraction) \\
sol_factic & Interstitial aerosol in convective wet removal tuning factor & 0.4 (fraction) & $0.2-0.8$ (fraction) \\
refindex_dust_sw & Visible imaginary refractive index for dust & 0.005 (dimensionless) & $0.001-0.01$ (dimensionless) \\
emis_DUST & Dust emission tuning factor & 0.35 (dimensionless) & $0.21-0.86$ (dimensionless) \\
emis_SEAS & Sea-salt emission tuning factor & 1.0 (dimensionless) & $0.5-2.0$ (dimensionless) \\
emis_SOAg & SOA (g) emission scaling factor & 1.5 (dimensionless) & $0.5-2.0($ dimensionless) \\
emis_SO_ & emission tuning factor for anthropogenic SO ${ }_{2}$ & 1 (dimensionless) & $0-2$ (dimensionless) \\
emis_BC & emission tuning factor for anthropogenic BC & 1 (dimensionless) & $0-3$ (dimensionless) \\
emis_POM & Emission tuning factor for anthropogenic POM & 1 (dimensionless) & $0-3$ (dimensionless) \\
emis_num_a1_surf & Tuning factor of aerosol number emission in accumulation mode & 1.0 (dimensionless) & $0.3-5.0$ (dimensionless) \\
emis_SO4f & tuning factor for fraction of SO S $_{2}$ emitted as sulfate & $2.5 \%$ (dimensionless) & $0-5 \%$ (dimensionless) \\
\hline
\end{tabular}

1989; Venables and Ripley, 2002). The interpreted variances are used to study and rank the relative contributions of each input parameter.

To evaluate the overall magnitude and global/localized variability due to the perturbations/uncertainties in the input parameters, ensemble output responses (e.g., FNET) are summarized. To demonstrate not only the global mean sensitivity but also sensitivity patterns at different locations, we consider both the global averaged and localized (e.g., at each grid point) output as response variables in this study.

\section{Results}

\subsection{Global mean FNET sensitivity}

Figure 1 shows the annual-mean anomalies of global mean FNET variance in response to the perturbations of 16 parameters from the 256 CAM5 simulations as described above. These 256 simulations are equally grouped into 8 sub-ranges (from small to large values) for each input parameter (i.e., 32 values are averaged in each sub-range) to rule out effects from the perturbation of other parameters. The minimum and maximum global mean FNET within each sub-range are shown as vertical bars. Anomalies are calculated by subtracting the 256-simulation mean from each individual simulation. The range of FNET in each sub-range of an individual input parameter results from perturbations of other parameters because the parameters are perturbed simultaneously based on QMC sampling. Figure 1 clearly demonstrates how input perturbations propagate through CAM5 to output variance. It also shows how the FNET response behaves when parameters fall in different sub-ranges.

Among the 256 simulations, FNET ranges from $-9.8 \mathrm{~W} \mathrm{~m}^{-2}$ to $3.5 \mathrm{~W} \mathrm{~m}^{-2}$ in response to the perturba- tions of the input parameters, compared to the default CAM5-simulated FNET of $1.9 \mathrm{~W} \mathrm{~m}^{-2}$. To better understand FNET responses to the perturbations of input parameters, the two components of FNET, the direct change of radiation fluxes in clear sky (FNETC) and the indirect cloud-induced change of radiation fluxes $(\mathrm{CF})(\mathrm{FNET}=\mathrm{FNETC}+\mathrm{CF}$ ), are also shown in Fig. 1. The variance of the long-wave (LW) and shortwave (SW) portion of FNETC and CF will be further discussed below. In the default CAM5 simulations, FNETC is $30.3 \mathrm{~W} \mathrm{~m}^{-2}$ and $\mathrm{CF}$ is $-28.4 \mathrm{~W} \mathrm{~m}^{-2}$. In the perturbed parameter simulations, FNETC ranges from $27.1 \mathrm{~W} \mathrm{~m}^{-2}$ to $32.2 \mathrm{~W} \mathrm{~m}^{-2}$ while $\mathrm{CF}$ ranges from $-39.0 \mathrm{~W} \mathrm{~m}^{-2}$ to $-26.8 \mathrm{~W} \mathrm{~m}^{-2}$. The variance in $\mathrm{CF}$ in the perturbed parameter simulations is much larger than that of FNETC and dominates the overall variance of FNET.

The GLM is applied to quantify the relative contribution of each parameter perturbation to the overall variance of FNET, FNETC, and CF. The $P$ value is obtained from the GLM analysis as explained above (Sect. 2.3.3). When a $P$ value estimated from the GLM for an input parameter is larger than a significance level of $95 \%$ (i.e., 0.05) it indicates that this input parameter is relatively insignificant to the overall variance of the response variable. It should be noted that the significance estimation of an input parameter is also dependent on the assigned perturbation range of this input parameter. Using this methodology, we identify the significant parameters for the variance of FNET, FNETC, and CF. Figure 2 shows the correspondence of global mean FNET, FNETC, and CF between the 256 CAM5 simulations and the 256 GLM predictions of these values based on the input parameters. The GLM model shown here includes both parameter effects and interactions. The GLM is able to predict the values of FNET, FNETC, and CF simulated by CAM5 with an $R^{2}$ of $0.98-0.99$, which indicates that $98-99 \%$ of the variance of CAM5 simulated FNET, FNETC, and CF is 

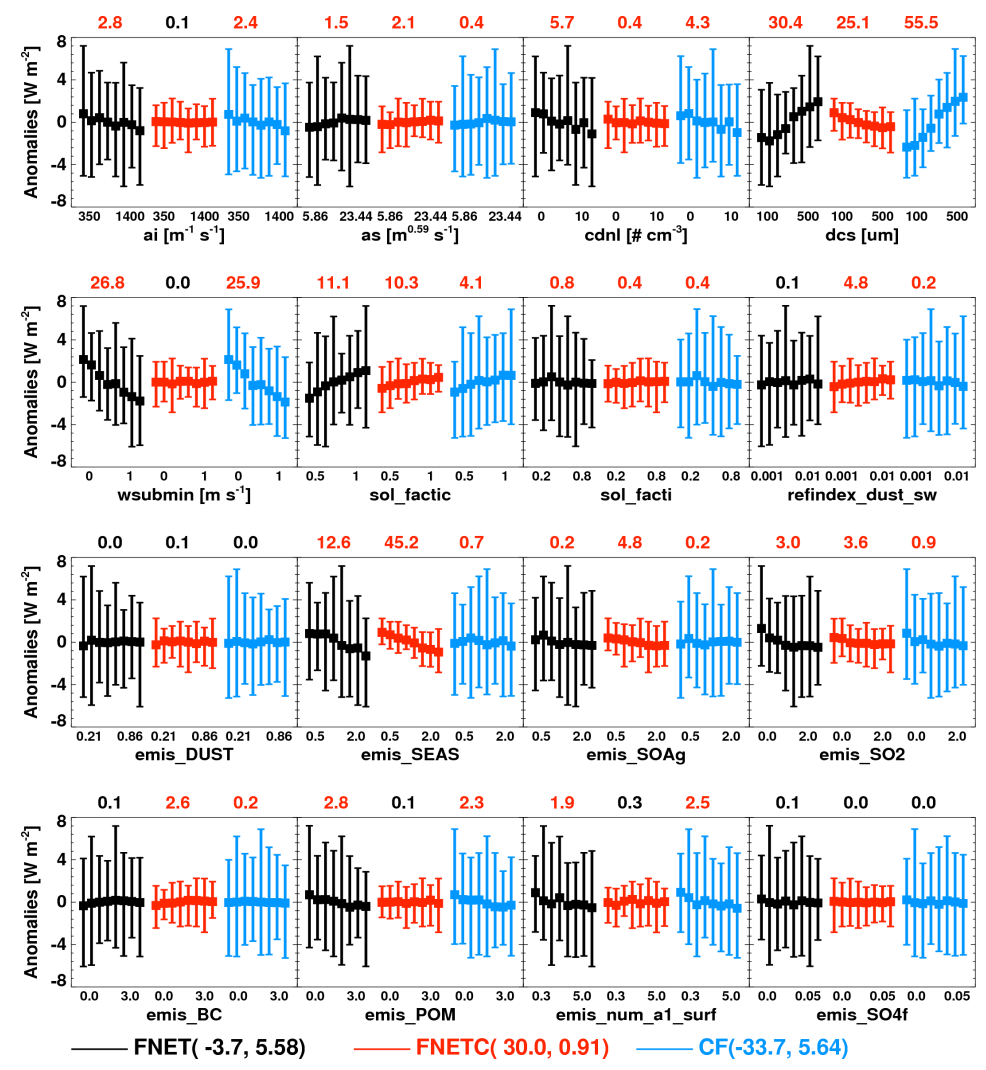

Fig. 1. Anomalies of variation of global mean FNET, clear-sky FNET (FNETC), and net (SW+LW) cloud forcing at TOA (CF) in response to the perturbations of 16 parameters from the 256 CAM5 simulations. The 256-simulation mean and variance are shown, respectively, in the parenthesis for FNET, FNETC, and CF. The numbers above each plot box represent the relative contribution (percentage) of each input parameter perturbation to the overall FNET, FNETC, and CF variations. Red means the contribution with $95 \%$ statistic significance.
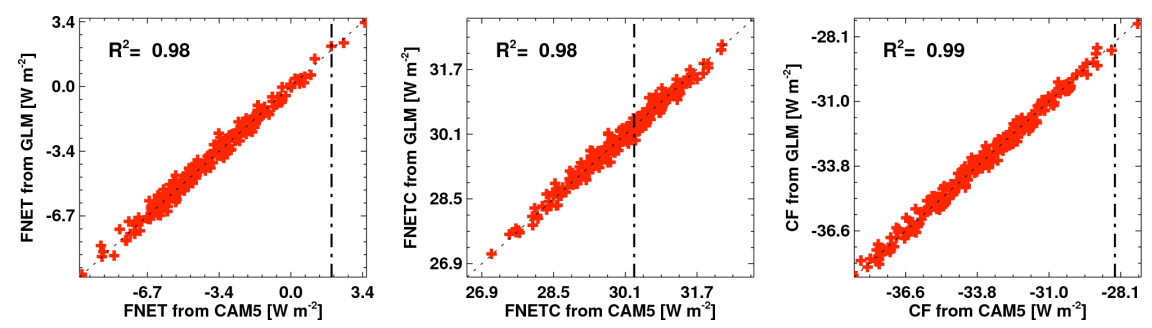

Fig. 2. GLM-fitted response variables versus the CAM5 simulations for FNET, FNETC, and CF. The black dash lines represent the values simulated by CAM5 with default parameters.

explained by the GLM. This confirms that the assumption of the polynomial relationships between inputs and outputs in the GLM is valid.

With the GLM, the relative contribution (in percentage) of each input parameter perturbation to the overall variance of FNET, FNETC, and CF can be quantified, as shown by the numbers in Fig. 1. It is indicated that the perturbation of dcs is the largest contributor (30.4\%) to the total variance of FNET, followed by wsubmin (26.8\%), emis_SEAS (12.6\%), sol_factic $(11.1 \%)$, cdnl $(5.7 \%)$, and other parameters with contributions less than $5 \%$. In addition, the parameters with contributions that are $95 \%$ statistically significant are highlighted in red (shown in Fig. 1). Perturbations of most internal model parameters except refindex_dust_sw are $95 \%$ statistically significant to the variance of FNET. For external emissions parameters, perturbations of sea-salt, SOA precursors, $\mathrm{SO}_{2}$, and $\mathrm{POM}$ emissions and the size distribution of emitted fossil fuel carbonaceous aerosols (POM and BC) are $95 \%$ statistically significant, but not the emissions of dust 

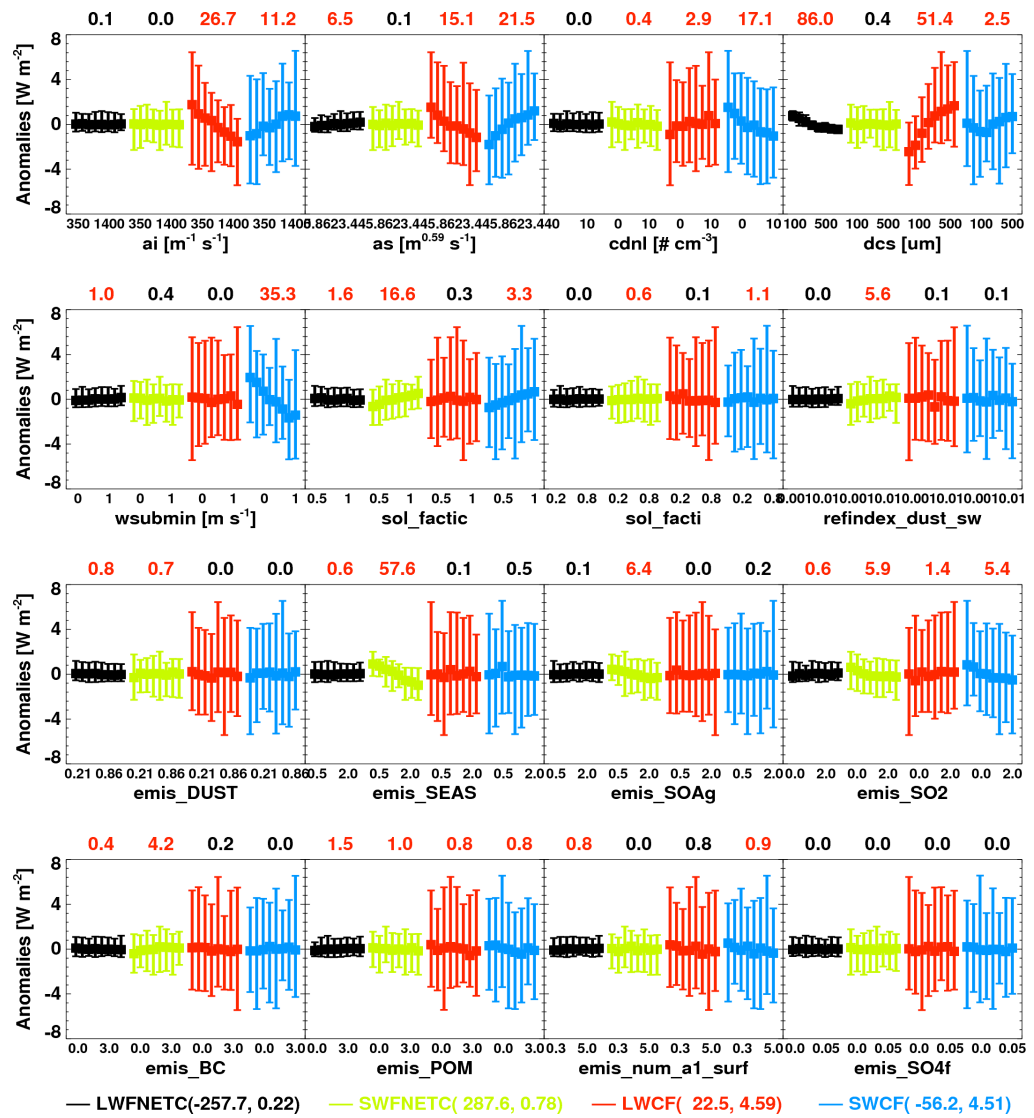

Fig. 3. Same as Fig. 1, but for anomalies of variation of global mean LW FNETC, SW FNETC, LWCF, and SWCF in response to the perturbations of 16 parameters from the 256 CAM5 simulations.

and $\mathrm{BC}$ and the fraction of sulfate aerosol in total sulfur emission.

In general, FNET increases with increasing dcs and sol_factic, but decreases with increasing ai, cdnl, wsubmin, emis_SEAS, emis_SO2, emis_POM, and emis_num_a1_surf. As the largest contributor to the FNET variance, dcs affects radiative fluxes at the TOA under both clear-sky and cloudy-sky conditions (i.e., both FNETC and $\mathrm{CF}$ ). The perturbation of des not only significantly contributes to $\mathrm{CF}$ variance (55.5\% of total variance), but also substantially contributes to FNETC (25\% of total variance). FNETC can be changed through direct scattering of incoming SW or indirect trapping of outgoing LW from surface temperature feedback. The $\mathrm{CF}$ change can be decomposed into SWCF and LWCF changes. Figure 3 shows the anomalies of the global mean variance of the LW and SW portions of FNETC and CF and Fig. 4 shows the anomalies of global mean variance of liquid water path (LWP), ice water path (IWP), water vapor path (WVP), and surface temperature (TSK), respectively, in response to the parameter perturbations. The $\mathrm{CF}$ increases with increasing dcs (i.e., increasing dcs leads to warming) mainly through changes in LWCF (51.4\% increase with dcs), with only relatively small changes $(2.5 \%)$ in SWCF. This may indicate that the changes in des mainly affect high clouds, which generally have much larger impact on LWCF than on SWCF. Increasing dcs reduces the rate of auto-conversion of cloud ice to snow, and thus increases IWP. Changes in dcs are the dominant contribution $(99.1 \%)$ to the IWP variance. Increasing dcs has a negligible impact on LWP. The increasing IWP traps more outgoing LW and hence increases LWCF (Fig. 3) and TSK (Fig. 4). The overall variance of TSK is $0.5 \mathrm{~K}$ with $52.7 \%$ contribution from the perturbation of dcs. The change in TSK mainly occurs over land areas, since the SST is prescribed in this study (will be discussed in Sect. 3.2). The change in ice clouds due to dcs can impact the mid- and upper-tropospheric water vapor budget through various ways such as affecting the water vapor deposition on ice crystals, affecting ice particle size and thus ice sedimentation, or by modifying the vertical transport of water vapor due to ice-cloud feedbacks on dynamics. The net effect of these interactions leads to increasing WVP with increasing dcs. The perturbation of dcs significantly affects LWFNETC variance with contribution of $86 \%$, but 

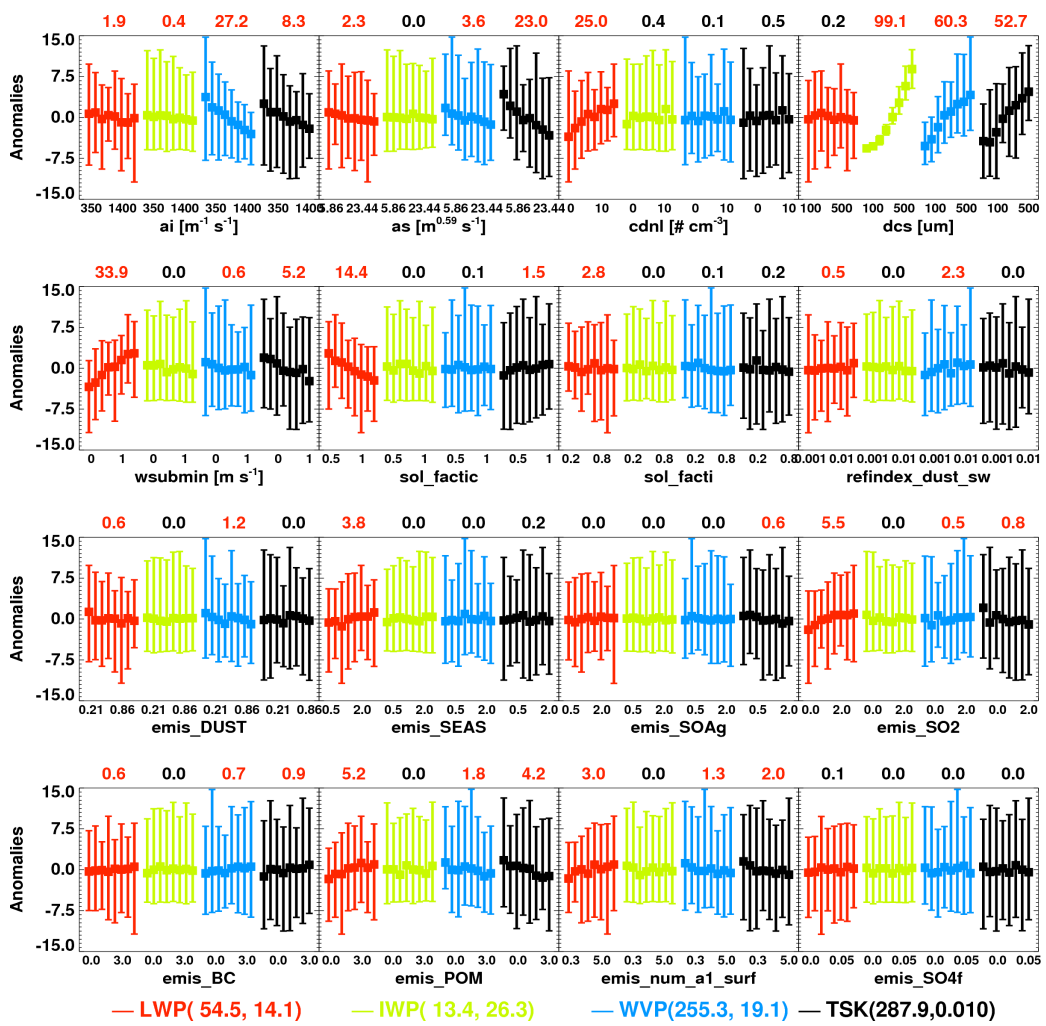

Fig. 4. Same as Fig. 1, but for anomalies of variation of global mean liquid water path (LWP), ice water path (IWP), water vapor path (WVP), and surface temperature (TSK) in response to the perturbations of 16 parameters from the 256 CAM5 simulations. The units for anomalies of LWP, IWP, WVP, and TSK are $\mathrm{g} \mathrm{m}^{2}, \mathrm{~g} \mathrm{~m}^{2}, \mathrm{hg} \mathrm{m}^{2}$, and $\mathrm{K} / 50$, respectively.

has negligible impact on SWFNETC. Although the increase of WVP with increasing dcs will reduce the outgoing LW and thus increase LWFNETC (less negative), the increase of TSK with dcs reduces LWFNETC (more negative) through increasing outgoing LW radiation under clear sky (Fig. 4). The overall LWFNETC change is dominated by the TSK change over the land (this will be discussed in Sect. 3.2). This study confirms why dcs has been used as one of the most effective tuning parameters for the TOA radiative forcing in CAM5 development (Gettelman et al., 2010).

The effect of wsubmin, the second largest contributor, is different from that of dcs. Perturbation of wsubmin contributes negligibly (close to $0 \%$ ) to FNETC variance, but $25.9 \%$ to $\mathrm{CF}$ variance, indicating that wsubmin reduces FNET primarily by reducing CF. CF significantly decreases with wsubmin primarily due to reduction of SWCF (more negative). The impact of wsubmin on LWCF is negligible. This may indicate that changes in wsubmin mainly affect low clouds that generally have much larger impact on SWCF rather than LWCF. The increase of wsubmin enhances the activation fraction of aerosols to cloud droplets, and thus increases the albedo through increasing the cloud droplet number concentration (i.e., aerosol first indirect effect) and lifetime of liquid clouds (i.e., aerosol second indirect effect).
While the perturbation of wsubmin significantly contributes to the LWP variance $(33.9 \%)$ via the aerosol second indirect effect, it has negligible impact on IWP variance. The perturbation of wsubmin also changes the surface temperature through modifying clouds. However, it mainly affects liquid clouds and has a relatively smaller impact on surface temperature than dcs. Therefore, wsubmin has a much smaller impact on LWFNETC and hence on FNETC compared to dcs. Generally, wsubmin mainly affects liquid clouds that have a larger impact on incoming SW, while des primarily affects ice clouds that have a larger impact on outgoing LW. Although both parameters affect clouds and significantly impact the CF, their feedbacks are different since the effect of clouds on TOA radiation depends on their heights and thicknesses (i.e., low clouds lead to cooling and high clouds lead to warming).

Compared to the perturbation of dcs, the perturbations of the other three cloud microphysics related parameters, ai, as, and cdnl, contribute merely $2.8 \%, 1.5 \%$, and $5.7 \%$, respectively, to the FNET variance. The perturbations of ai and as contribute to $26.7 \%$ and $15.1 \%$, respectively, of LWCF variance, and to $11.2 \%$ and $21.5 \%$, respectively, of SWCF variance. In general, the changes of ai and as have comparable impact on CF; however, ai has a larger impact on 
high clouds and hence on LWCF and a smaller impact on low clouds and hence on SWCF than as. Increasing ai and as reduces the IWP (through ice and snow sedimentation) and the LWP (through microphysical processes in mixedphase clouds, e.g., Bergeron-Findeisen process by falling ice and snow), weakens the LWCF (less positive) and SWCF (less negative) at a similar magnitude, and thus results in a relatively small impact on CF and FNET. Increasing both ai and as reduces TSK, but has relatively small impact on LWFNETC and SWFNETC. Varying cdnl has a much larger impact on SWCF $(17.1 \%)$ than on LWCF $(2.9 \%)$ and a negligible impact on FNETC. This indicates that cdnl has a larger impact on low clouds than on high clouds. Increasing cdnl significantly increases the LWP and hence CF by increasing the cloud droplet number concentration to the lower limiter at remote regions where cloud droplet number is limited by the availability of $\mathrm{CCN}$.

Increasing the solubility factor of interstitial aerosols (with respect to convective cloud-borne aerosol) (sol_factic) increases the efficiency of wet removal of aerosols by convective rain, and thus reduces overall aerosol concentrations, as well as cloud albedo and the LWP (e.g., Wang et al., 2013). Therefore, the increase of sol_factic enhances SWFNETC with a contribution of $16.6 \%$ to the SWFNETC variance. The $\mathrm{CF}$ (mainly from SWCF) also increases with sol_factic. However, the solubility factor of stratiform cloudborne aerosols (sol_facti) has a negligible impact on both FNETC and CF likely because cloud-borne aerosols in stratiform clouds are taken out of the atmosphere too rapidly by wet scavenging in CAM5 (Liu et al., 2011). The increase of refindex_dust_sw (visible imaginary refractive index of dust) augments global mean SWFNETC due to the enhancement of dust SW absorption, but this has a statistically insignificant impact on global mean FNET with its perturbed range (0.001-0.01).

Among the external parameters, increasing the mass emissions of sea salt, dust, anthropogenic $\mathrm{SO}_{2}$, and POM as well as increasing the number emission of aerosol in accumulation mode (by reducing the emission size) increases the aerosol optical depth and CCN number concentrations. The perturbation of emis_SEAS (i.e., sea-salt emission) contributes most significantly $(12.6 \%)$ to the global mean FNET variance, mostly through its contribution $(45.2 \%)$ to the FNETC variance. The increase of sea-salt emission reduces FNETC by scattering more solar radiation. Other emission parameters including dust and anthropogenic emissions have a much smaller impact on FNET variance than sea-salt emission, likely due to the fact that their emissions occur primarily over the continents where aerosol concentrations are relatively more abundant. The contributions of emission perturbations (except emis_SO4f) are also normalized by their perturbation scale (i.e., by the perturbation range of each emission parameter). The results are summarized in Table 2 and show that the dominant contribution of the emis_SEAS perturbation among emission parameters to global mean FNET vari- ance stems from its contribution to the global mean FNETC. In terms of $\mathrm{CF}$, the perturbation of each emission parameter has a comparable contribution.

By using the SA approach in this study, we are able to quantify the interactions among the 16 input parameters. When a perturbation of one parameter enhances or weakens the sensitivity of another parameter, interactions occur. Figure 5 shows the relative contributions of perturbations of each parameter and their interaction effect to the FNET, FNETC, and $\mathrm{CF}$ variance. The main effect (i.e., without interaction effect) of perturbations of individual parameters contributes $>95 \%$ of the FNET, FNETC, and CF variance, while the interaction effect contributes only $\sim 3 \%$ of their variance. In terms of the variance of global mean FNET, FNETC, and CF, the interaction effect among the 16 selected input parameters is inconsequential in CAM5.

\subsection{Spatial distribution of FNET and its uncertainty}

Changes in both the global mean and the spatial distribution of FNET are important for driving climate change, particularly at the regional scale. Figure 6 shows the spatial distribution of the variance of FNET, FNETC, and CF in the perturbed parameter simulations. The FNET variance shows large spatial variability. Relatively large FNET variance occurs over the southern oceans (south of $60^{\circ} \mathrm{S}$ ), northern Pacific, northern Atlantic, East Asia, Tibetan Plateau, southern and northern Africa, and South America while the FNET variance over the polar-regions is relatively small, particularly over the Antarctic. The CF variance dominates the FNET variance over most regions, which is consistent with the analysis of global mean FNET. The relatively large FNET variance over the oceans, southern Africa, and South America is mainly due to the large variance of CF over these regions. Relatively large FNETC variance occurs over North Africa, East Asia, and the Tibetan Plateau. It is interesting to note that FNETC also has relatively large variance over the Arctic, where the variance of CF and FNETC offset each other so that the FNET variance is small. The contributions of each parameter perturbation to these features of spatial variability are discussed below.

To quantify the variance contributions from the 16 input parameters to the spatial variability, the GLM analysis is conducted for the FNET of each grid box in the same way as it was applied for the global mean FNET in Sect. 3.1. Figure 7 shows the spatial distributions of $R^{2}$ of the GLM models for FNET, FNETC, and CF. In general, the GLM models can predict the FNET, FNETC, and CF variance over most regions at latitudes lower than $70^{\circ}$. High $R^{2}$ values $>0.9$ indicate that most of the output total variance can be explained by the input parameters over these regions. The regions with relatively lower $R^{2}$ values $(0.5 \sim 0.8)$, for example, higher latitudes and Australia, generally also have smaller variance of FNET, FNETC, and CF (Fig. 6). Therefore, these regions are less interesting for the characterization 
Table 2. Normalized changes of radiative fluxes due to perturbations of emission parameters in CAM5. The values in parenthesis are the relative contributions (\%) of parameter perturbations to the total variance of FNET resulting from perturbation of emission parameters.

\begin{tabular}{lrrrrrrr}
\hline & Dust & Sea salt & SOAg & SO $_{2}$ & BC & POM & num_a1_surf \\
\hline FNET & $0.06(0.2)$ & $0.6(40.7)$ & $0.07(0.6)$ & $0.2(7.3)$ & $0.03(0.2)$ & $0.1(4.5)$ & $0.07(2.0)$ \\
FNETC & $0.05(0.3)$ & $0.4(53.1)$ & $0.1(5.6)$ & $0.09(3.2)$ & $0.05(1.5)$ & $0.01(0.06)$ & $0.01(0.1)$ \\
LWFNETC & $0.07(25.6)$ & $0.02(8.3)$ & $0.01(1.4)$ & $0.02(6.3)$ & $0.01(2.8)$ & $0.02(10.4)$ & $0.01(3.5)$ \\
SWFNETC & $0.1(1.4)$ & $0.5(50.6)$ & $0.2(5.6)$ & $0.1(3.9)$ & $0.06(1.8)$ & $0.03(0.4)$ & $0.003(0.01)$ \\
CF & $0.06(0.7)$ & $0.1(6.8)$ & $0.07(2.0)$ & $0.1(6.6)$ & $0.04(0.98)$ & $0.1(11.2)$ & $0.08(7.8)$ \\
LWCF & $0.06(1.4)$ & $0.05(2.0)$ & $0.03(0.6)$ & $0.1(20.8)$ & $0.03(2.0)$ & $0.06(7.9)$ & $0.04(5.1)$ \\
SWCF & $0.06(0.6)$ & $0.1(4.2)$ & $0.06(1.7)$ & $0.3(34.4)$ & $0.01(0.1)$ & $0.06(3.4)$ & $0.04(2.4)$ \\
\hline
\end{tabular}

* The normalized variation of radiative fluxes is calculated through dividing parameter-induced variation of radiative fluxes by the scale range of emission change. Therefore, the unit is $\mathrm{W} \mathrm{m}^{-2} /($ unit scale change).

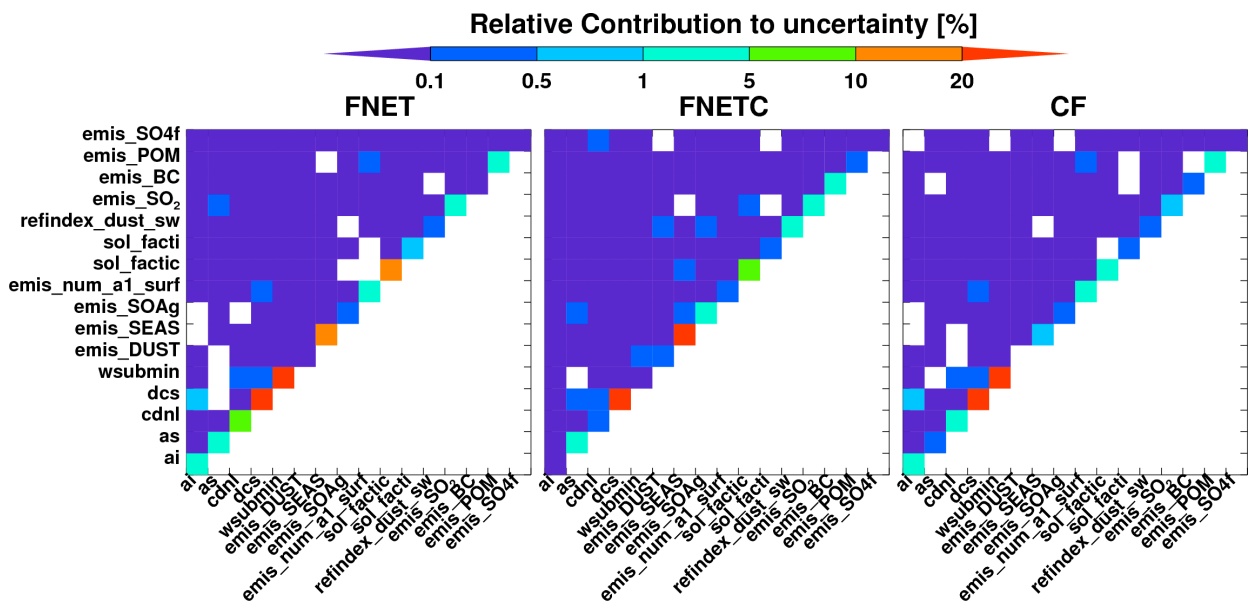

Fig. 5. Relative contributions (percentage) of perturbations of individual parameter and their interactions to the variations of FNET, FNETC, and CF estimated by the GLM.

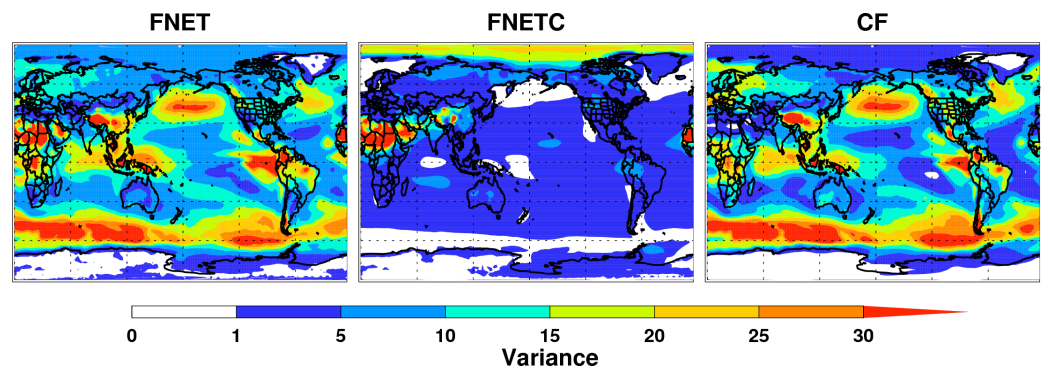

Fig. 6. Global spatial distribution of variance of FNET, FNETC, and CF (unit in $\mathrm{W}^{2} \mathrm{~m}^{-4}$ ) in response to the perturbations of 16 parameters from the 256 CAM5 simulations.

of sources of variance. Figures 8 and 9 show the global spatial distribution of the absolute and relative contributions of the 16 input parameters to the FNET variance estimated by the GLM. Note that the FNET variance in any given grid box can be affected not only by the localized processes but also by the processes occurring at other grid boxes. For example, the aerosol at any location has contributions from both longrange transport and physical and chemical transformations, so the impact of an aerosol related parameter in a given grid box depends on the integrated effect of that parameter. The global spatial distributions of the absolute contributions of each of the perturbed parameters to the FNETC and CF variance estimated by the GLM are shown in Figs. 10 and 11.

Among all parameters, the perturbation of des is the largest contributor to the FNET variance over many regions of the globe, such as the North Pacific and the southern oceans 


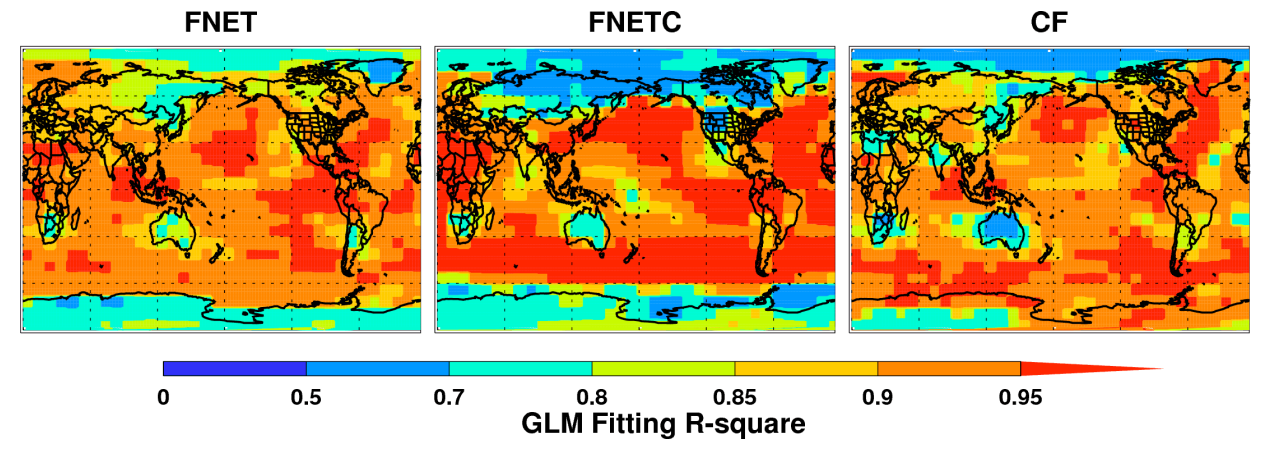

Fig. 7. Spatial distributions of $R^{2}$ of the GLM models for FNET, FNETC, and CF.
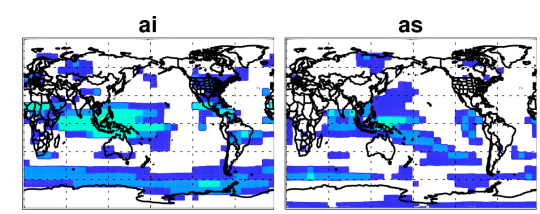

wsubmin
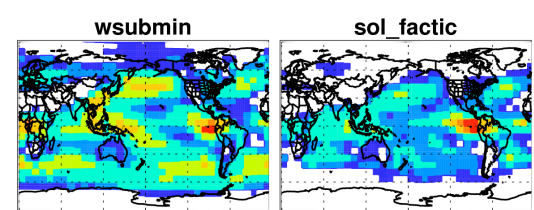

emis_DUST
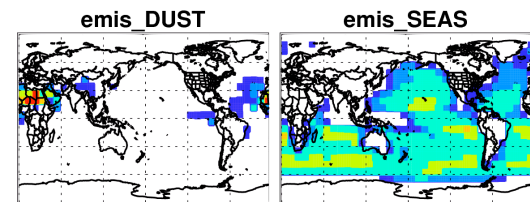

emis_POM

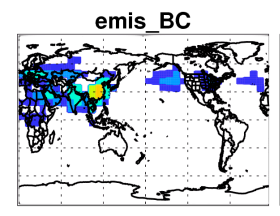

0
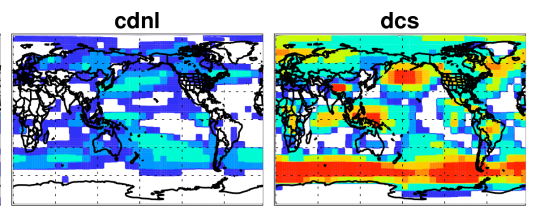

sol_facti

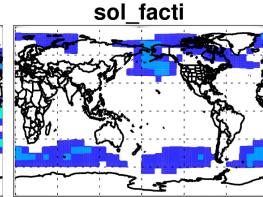

refindex_dust_sw

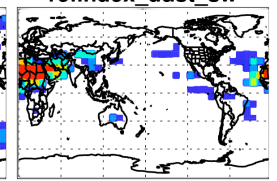

emis_SOAg

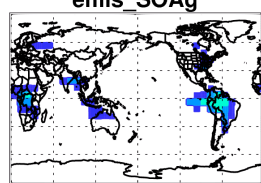

emis_SO2

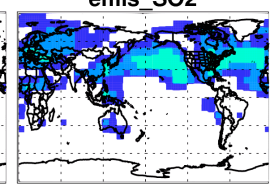

emis_num_a1_surf emis_SO4f
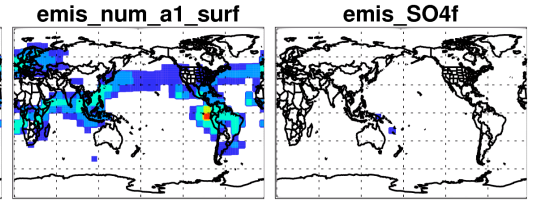

Fig. 8. Global spatial distribution of absolute FNET variance (unit in $\mathrm{W}^{2} \mathrm{~m}^{-4}$ ) in response to the perturbation of each of the 16 input parameters predicted by the GLM.

$\left(50-70^{\circ} \mathrm{S}\right)$, with relative contributions of $>50 \%$ (Fig. 9). The perturbation of des also makes significant contributions to the FNET variance over the tropical Pacific, North Atlantic, and North and South America. In most regions, the des perturbation contributes to the FNET variance primarily from its impact on CF, which is consistent with the impact of dcs on global mean FNET variance. The primary impact of dcs stems from its effect on IWP over regions containing large amounts of ice clouds (see Fig. S1 in the Supplement). However, the effect of des perturbations is different over the Arctic. There, perturbations of dcs affect the FNET variance mainly through impacts on TSK and hence FNETC (Fig. S2 in the Supplement). The relative contribution of perturbations of as and ai to the FNET variance is much less than that of dcs over most regions and is mainly due to their impact on CF. The perturbation of cdnl contributes $<10 \%$ to the FNET variance over most regions of the globe and occurs mainly due to its impact on CF. The four cloud microphysics parameters are the main contributors to the FNET variance over polar regions because of their impact on liquid (from cdnl) and ice (from dcs, ai, and as) clouds (refer to Figs. S1 and S3 in the Supplement).

The perturbation of wsubmin significantly contributes to the FNET variance over East Asia, the tropical Pacific, and 

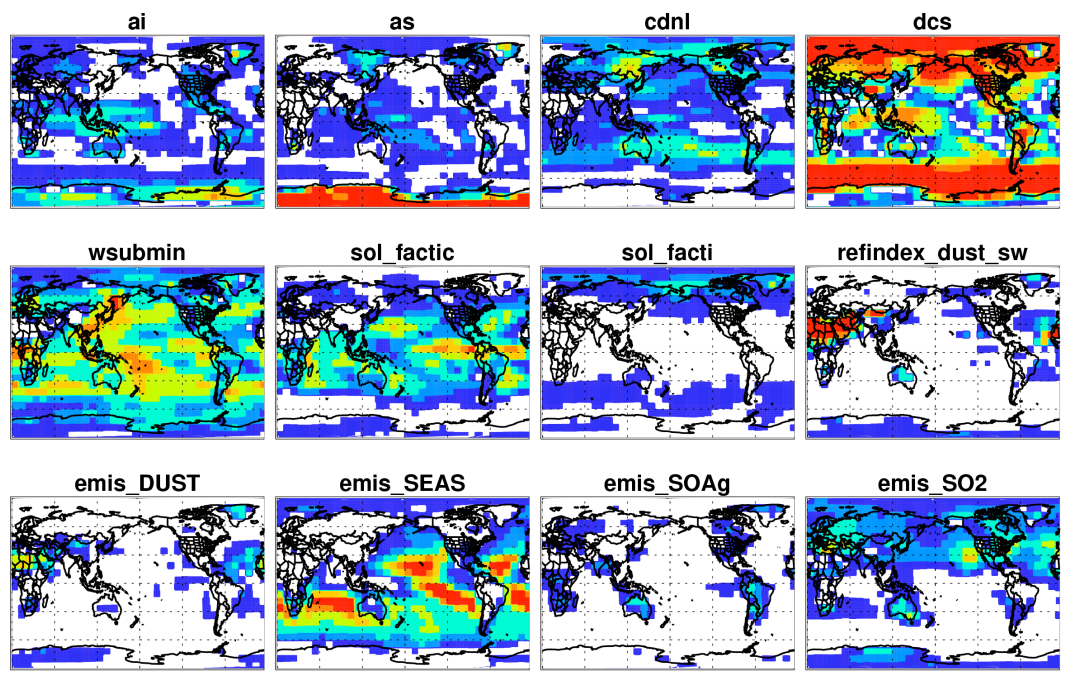

emis_SEAS
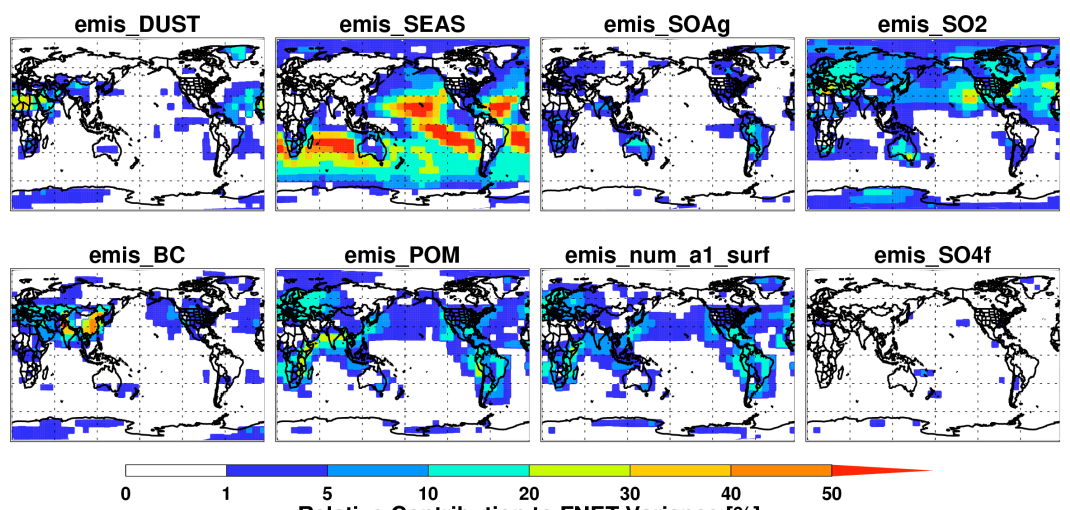

emis_POM
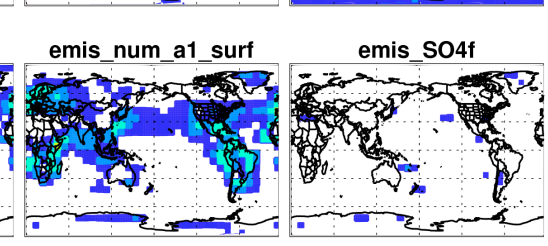

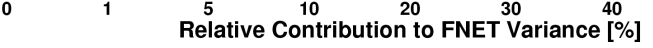

50

Fig. 9. Global spatial distribution of percentage of FNET variance in response to the perturbation of each of the 16 input parameters predicted by the GLM.

the outflow regions of East Asia over the Pacific and North America over the Atlantic. The wsubmin impact on FNET occurs mainly through impacts on LWP and thus CF by changing cloud droplet number concentrations (i.e., aerosol indirect effects). The impact is mainly over the regions where there are frequent occurrences of liquid-containing clouds (e.g., along the North Pacific and Atlantic storm tracks) and sufficient numbers of CCN (see Fig. S3 in the Supplement). The significant contribution of the sol_factic perturbation to the FNET variance stems chiefly from its impact on CF at mid- and lower latitudes, where convection is more likely to occur and more aerosols are subject to wet removal. It has the largest contribution over the Pacific Ocean near the Amazon Basin of South America. The absolute contribution of sol_facti perturbation to the FNET variance is small (1-5\%) throughout the globe.

The perturbation of refindex_dust_sw is the largest contributor (> 50\%) to the FNET variance over the Saharan and Asian deserts. Its impact is mostly confined near the desert regions. It affects the FNET variance principally through its impact on FNETC through the direct effect of dust but also partly due to its impact on CF via the semi-direct effect of dust. The perturbation of dust emission (emis_DUST) contributes $10-30 \%$ to the FNET variance over the Saharan and Asian deserts mainly through its impact on FNETC. The contribution is mostly confined to the desert regions, but the
FNET variance over the North Atlantic is also affected due to the Sahara Air Layer (SAL) (e.g., Dunion and Velden, 2004). The perturbation of sea-salt emission (emis_SEAS) dominates the FNET variance over the oceanic regions at midand lower latitudes with strong sea-salt emissions. Its contribution primarily stems from its impact on the FNETC variance, except over the Southern Ocean at $\sim 60^{\circ} \mathrm{S}$, where its contribution to the $\mathrm{CF}$ variance by acting as $\mathrm{CCN}$ is larger.

The contributions of perturbations of anthropogenic emissions are larger over continents than over oceans. The perturbation of anthropogenic $\mathrm{SO}_{2}$ emission (emis_SO2) has a significant impact on the FNET variance over the Northern Hemisphere (NH), in particular over the North Pacific and Atlantic where its contribution reaches $40 \%$ of the FNET variance. The significant impact of emis_SO2 (anthropogenic $\mathrm{SO}_{2}$ emission) occurs over both the source (continent) and remote (oceanic) regions. Over the continents, emis_SO2 perturbation contributes to the FNET variance principally through FNETC (direct effect) while over the ocean it is mainly through CF (indirect effect). Among all the anthropogenic emissions, the perturbation of $\mathrm{BC}$ emission is the largest contributor (> 30\%) to the FNET variance over East China and North India. The perturbation of emis_BC also affects $\mathrm{CF}$ through the semi-direct and indirect effect of BC. The perturbations of emis_POM and emis_num_a1_surf lead to significant FNET variance through impacts on CF 


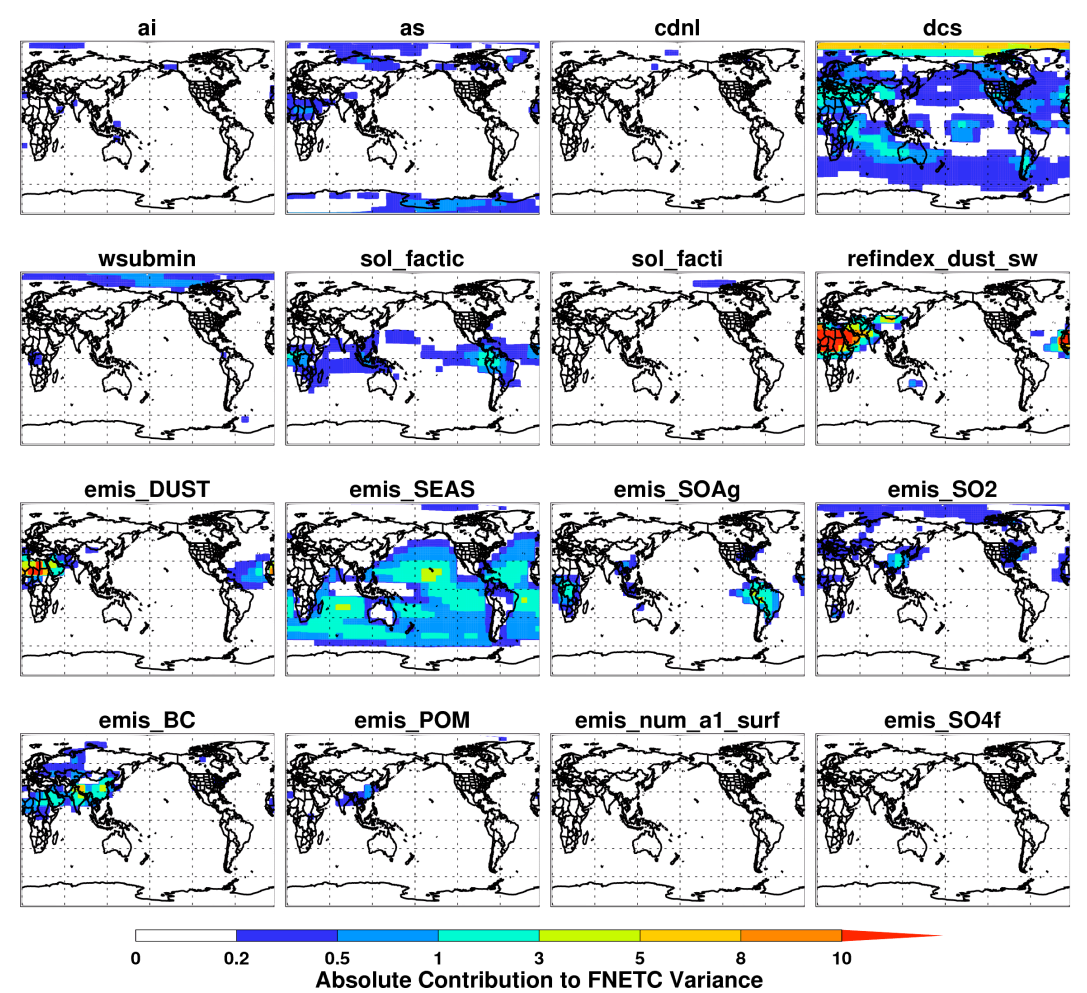

Fig. 10. Global spatial distribution of absolute FNETC variance (unit in $\mathrm{W}^{2} \mathrm{~m}^{-4}$ ) in response to the perturbation of each of the 16 input parameters predicted by the GLM.

over the biomass burning regions and $\mathrm{NH}$ continental outflows. The perturbation of emis_SOAg leads to relatively small FNET variance through FNETC with relative contributions of $\sim 10 \%$. The contribution of emis_SO4f perturbation is negligible throughout the globe. The impact of these emission parameters on the FNETC variance is larger over aerosol source regions (i.e., continents), while their impact on the CF variance is larger over the continental outflow regions over the ocean, indicating the higher susceptibility of marine clouds to aerosol perturbations.

Note that the relative contributions of emission perturbations to the FNET variance are dependent on the prescribed perturbation range of emissions. In one SA, the contributions of emission perturbations are normalized by the standard deviations of emission parameters. In this case, the contribution is much less dependent on the perturbation ranges. Figure 12 shows the global spatial distribution of normalized percentage of FNET variance in response to the perturbation of six emission parameters predicted by the GLM. We found that the spatial distributions of normalized contributions are not significantly different from the ones shown in Fig. 9 for relative contributions of FNET variance from the 16 selected input parameters. Notably, it is difficult to normalized contributions from all parameters because cloud microphysics parameters have different physics meanings and units from those used for emissions.
Similar to the analysis of interaction effects for global mean FNET (Fig. 5), the individual and interaction effects analyzed using the GLM are shown in Fig. 13. The analysis is conducted for each grid box globally. The GLM predicted total variance of FNET is similar to the CAM5 simulated variance (Fig. 6) and consistent with the high $R^{2}$ values (Fig. 7). In general, individual effects dominate the total effect. The interaction effect is relatively small over most regions of the globe, except in the polar regions and Australia, where the interaction contribution can reach more than $50 \%$. The reason for the large impact of interaction effects in these regions is unknown. However, the FNET variance is relatively small over these regions. The parameter interaction contributes to $<15 \%$ of the FNET variance over most regions of the globe. The spatial distribution of the interaction effect on FNETC and CF are consistent with that of FNET.

\section{Discussions}

In this study, we developed and applied an SA framework to analyze the variance of simulated radiative flux (FNET) at the top of atmosphere (TOA) in the present-day climate due to perturbations of model internal parameters related to cloud microphysics and aerosol processes, and external parameters related to aerosol and its precursor gas emissions in 

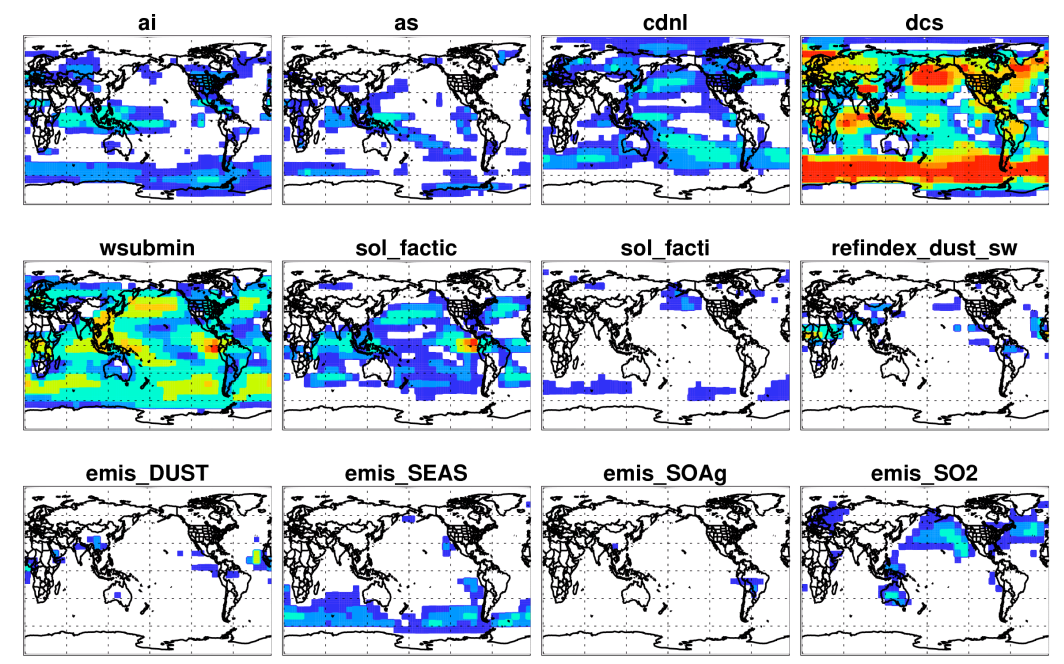

emis_SEAS

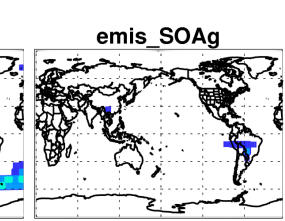

emis_SO2

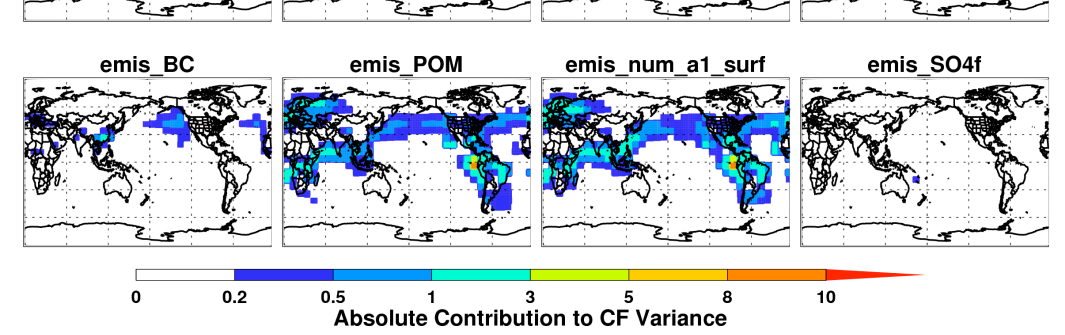

Fig. 11. Global spatial distribution of absolute $\mathrm{CF}$ variance (unit in $\mathrm{W}^{2} \mathrm{~m}^{-4}$ ) in response to the perturbation of each of the 16 input parameters predicted by the GLM.

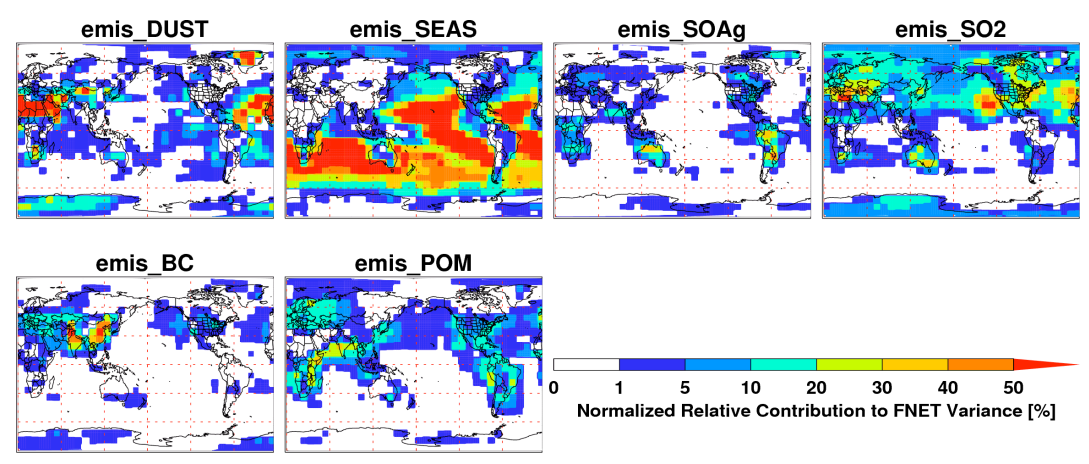

Fig. 12. Global spatial distribution of normalized percentage of FNET variance in response to the perturbation of six emission parameters predicted by the GLM.

the state-of-the-art global climate model CAM5. The analysis demonstrates the high sensitivity of FNET to the 16 input parameters within the perturbed ranges. FNET simulated by CAM5 varies from $-9.8 \mathrm{~W} \mathrm{~m}^{-2}$ to $3.5 \mathrm{~W} \mathrm{~m}^{-2}$ in response to the perturbations of input parameters, compared to a value of $1.9 \mathrm{~W} \mathrm{~m}^{-2}$ simulated with default parameter values. The analysis indicates a change in FNET between -11.7 and $1.6 \mathrm{~W} \mathrm{~m}^{-2}$ (compared to FNET from the standard CAM5 simulation). This is much larger than the range of -1.8 to $-0.1 \mathrm{~W} \mathrm{~m}^{-2}$ given for uncertainty in aerosol radiative forcing in the IPCC AR4 report. However, it should be noted that this study does not show the sensitivity of radiative forcing (i.e., $\triangle$ FNET from pre-industrial to present-day) to the selected parameters, which is worthy of further investigation. The FNET change is dominated by changes in CF, indicating the importance of improving cloud parameterizations in CAM5. We certainly realize here that this large FNET change is dependent on the perturbation range assigned by the model developers.

Our variance-based analysis shows that the GLM reproduces global mean and spatial patterns of CAM5-simulated variance of FNET and its components, $\mathrm{CF}$ and FNETC. 

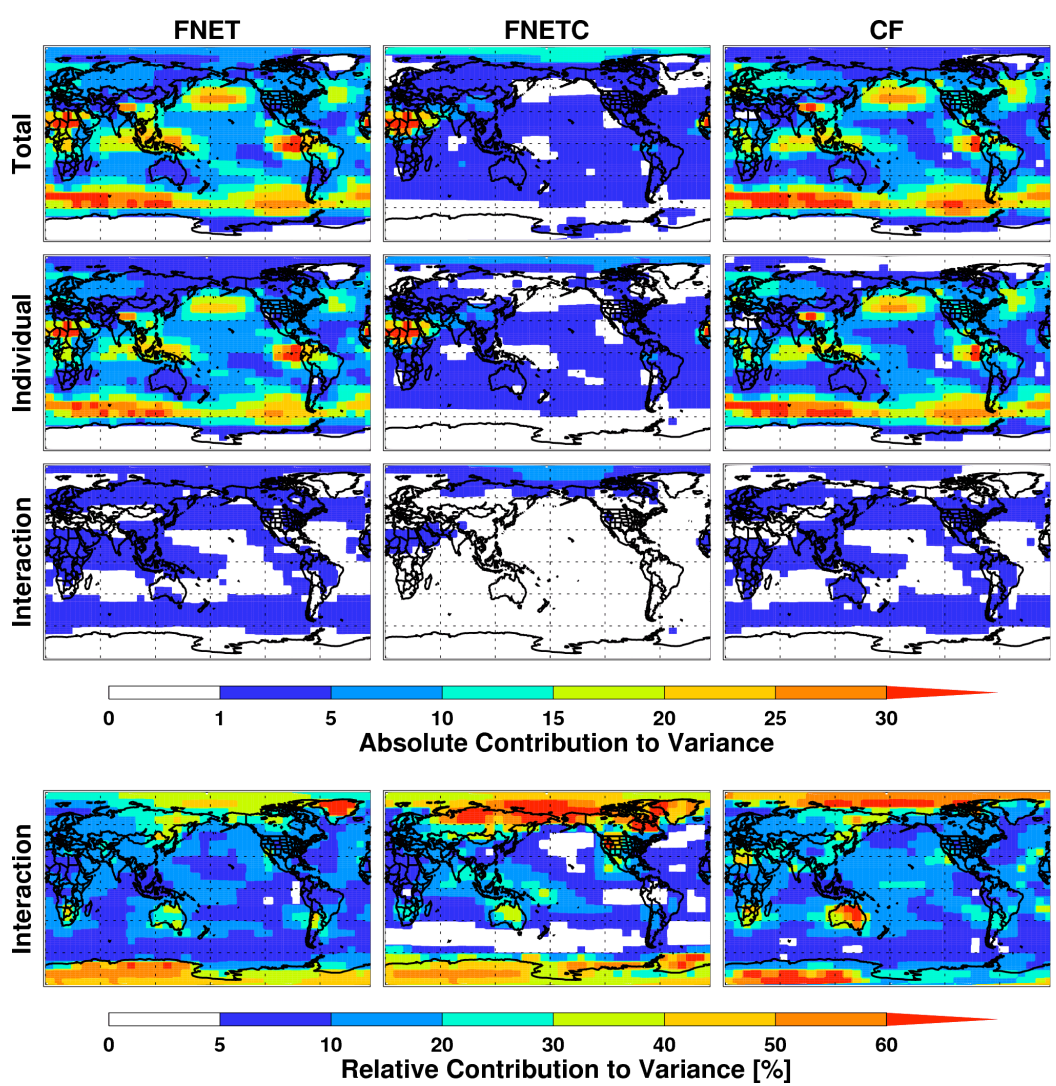

Fig. 13. Global spatial distribution of absolute variance of FNET, FNETC, and CF (unit in $\mathrm{W}^{2} \mathrm{~m}^{-4}$ ) in response to the total, main, and interaction effects of perturbations of 16 input parameters predicted by the GLM, the percentage of variance of FNET, FNETC, and CF in response to the interaction effect.

The variance of the LW and SW components of FNETC and CF is also analyzed. The results show that the global mean FNET variance is dominated by the CF variance with the assigned parameter ranges. Most selected cloud microphysics and emission related parameters are found to have statistically significant impacts on the global mean FNET. Cloud microphysics related parameters significantly affect both high and low clouds and hence CF; des mainly affects high clouds and hence CF through LWCF; ai has a larger impact on high clouds and hence LWCF and a smaller impact on low clouds and hence SWCF than as; cdnl mainly affects low clouds and hence SWCF. The results confirm des (i.e., auto-conversion size threshold for ice to snow) as one of the most effective tuning parameters for the TOA radiative forcing in CAM5. The other three cloud microphysics parameters, associated with the fall speed of cloud ice and snow and the limiter of cloud droplet number, have a smaller impact on the global mean FNET. Overall, these four cloud microphysics related parameters all have larger impact on high clouds and hence LWCF. The increase of wsubmin (i.e., minimum limit of subgrid in-cloud vertical velocity) increases the albedo through increasing the cloud droplet number concentration (i.e., aerosol first indirect effect) and lifetime of liquid clouds (i.e., aerosol second indirect effect); wsubmin mainly affects SWCF through its impact on low clouds. The emission parameters are found to have a relatively small impact on the global mean FNET, except the one related to seasalt emissions, because their impact is mostly confined over the source region.

In terms of spatial distribution, the FNET variance due to the parametric perturbation has strong heterogeneous geographic distribution. The spatial distribution of the FNET variance contribution of some input parameters has a clear localized effect that primarily impacts the area where that parameter is in effect. For example, the FNET variance contribution from des perturbation is mainly over the ice-cloud regions. The contribution from perturbations of sea-salt and dust emissions shows up primarily in windy marine and desert regions, respectively. However, the perturbation of some parameters has non-local impacts on FNET variance. For example, aerosol wet scavenging can affect the FNET variance in regions without clouds, and the anthropogenic emission of $\mathrm{SO}_{2}$ influences FNET over the remote oceanic regions. This is generally consistent with the findings by Lee et al. (2012 and 2013). They used a different SA approach (i.e., Gaussian emulation technique and Monte Carlo 
sampling approach) and found that the effects of emission parameters (such as sea salt) are normally localized to the place where that parameter is acting while the effects of model parameters (such as the wet scavenging parameter) have nonlocal impacts.

The SA framework used in this study is designed with the capability to quantify the interactions among the parameters. However, the analysis indicates a relatively small contribution of interaction effects among the selected 16 parameters to the overall variation of the global mean FNET $(\sim 3 \%)$ and to the FNET variation over most regions of globe $(<15 \%)$. This relatively small interaction effect may be partially due to the relatively large group of selected parameters. Lee et al. (2012) found the interaction effect among the eight selected parameters contributes to $30-50 \%$ of the overall uncertainty in modeling CCN. However, Lee et al. (2013) extended the eight parameters to 28 and found the contribution of interaction effects significantly reduces to $<20 \%$. This may indicate that the relative contribution of the parameter interaction to the overall uncertainty will be generally small when a large group of parameters are taken into SA.

Some clarification of the results in this study should be made. First, the uncertain range of anthropogenic aerosol and precursors emissions may be different from the perturbation range we prescribed here. The investigated ranges of emissions are selected for SA rather than uncertainty quantification. Second, the impact of parametric perturbation on the FNET variance does not include SST feedbacks since prescribed SST were used in this study, although we note that it is a standard method to calculate radiative flux perturbations with prescribed SST. Third, in this study we examine the uncertain parameters related to cloud microphysics and aerosol processes as the first step. We note that there still are other uncertainty parameters in CAM5 that can affect the modeled FNET. However, the approach in this study can be readily extended to a larger set of parameters for other parameterizations and eventually also other models, providing a framework for the quantifiable analysis of model sensitivity. Finally, the conclusions in this study are limited to the CAM5 model, but such systematic studies may be useful for other GCMs as well. In fact, some previous studies also investigated the impact of uncertainty parameters in individual climate models (e.g., Lohmann and Ferrachat, 2010; Lee et al., 2012, 2013), and their findings have benefited the climate modeling community.

This study efficiently investigates 16 uncertainty parameters simultaneously compared to the OTA SA approach that generally examines a limited number of parameters (e.g., four parameters in Lohmann and Ferrachat, 2010). The relative contribution of parameter interaction to the overall uncertainty is also quantified. Compared to the OTA SA approach, the more comprehensive approach used in this study not only estimates the contribution of each parameter to model sensitivity but also provides its statistical significance, which is rarely obtained by the OTA SA approach due to the limited sampled space of parameter uncertainty. Therefore, this study highlights the benefits of using a more comprehensive SA approach to understand the parametric uncertainties in climate models. Lee et al. $(2012,2013)$ focused primarily on the contribution of the aerosol-CCN related parameters to uncertainty in modeling CCN. Lee et al. (2013) admitted that cloud-related parameters might also play an important role in determining aerosol indirect effects. The current study found that emission and aerosol related parameters generally have smaller impacts on the global mean FNET than cloud microphysics related parameters. Although this finding may be model-dependent, it highlights the importance of including cloud related parameters in understanding uncertainties in modeling aerosol radiative forcing (direct and indirect).

This study also highlights that the next step in reducing modeling uncertainty through calibration requires a complete understanding of the model behavior within the parameter uncertainties (e.g., identifying a set of model parameters that best matches observations within defined criteria) (Yang et al., 2012, 2013). Although anthropogenic and natural emissions are uncertain and important to accurately simulate FNET change, particularly at the regional scale, within the ranges (see Table 1) investigated in this study, the impact of the model internal parametric uncertainties is higher in terms of simulating global mean CF and FNET. More studies are needed to improve the cloud microphysics and sub-grid cloud variability in GCMs. Analysis of spatial distribution of FNET variance can provide useful guidance for planning measurement campaigns to efficiently reduce uncertainty in modeling FNET. In addition, this study indicates the high sensitivity of FNET to model internal parameters. Although future climate change is commonly projected by a climate model using its "standard" set of internal parameters that can reproduce the historical climate, there may exist another set of internal parameters that can reproduce a similar historical climate but produce a significantly different future climate.

\section{Supplementary material related to this article is available online at http://www.atmos-chem-phys.net/13/ 10969/2013/acp-13-10969-2013-supplement.pdf.}

Acknowledgements. This research was supported by the Office of Science of the US Department of Energy (DOE) as part of the Earth System Modeling Program and the Regional \& Global Climate Modeling (RGCM) program. This research used computing resources from the National Energy Research Scientific Computing Center, which is supported by the DOE Office of Science under Contract No. DE-AC02-05CH11231. Pacific Northwest National Laboratory is operated by Battelle Memorial Institute for the DOE under contract DE-AC05-76RL01830. We thank Athanasios Nenes for the editorial help. Insightful comments offered by the two anonymous referees are highly appreciated. 
Edited by: A. Nenes

\section{References}

Abdul-Razzak, H. and Ghan, S. J.: A parameterization of aerosol activation, 2. Multiple aerosol types, J. Geophys. Res., 105, 68376844, 2000.

Anderson B., Knight, J. F., Ringer, M. A., Desser, C., Phillips, A., Yoon, J.-H., and Cherchi, A.: Climate Forcings and Climate Sensitivities Diagnosed from Atmospheric Global Circulation Models, Clim. Dynam., 35, 1461-1475, doi:10.1007/s00382-0100798-y, 2010.

Anderson B. T., Knight, J. R., Ringer, M. A., Yoon, J.-H., and Cherchi, A.: Testing for the Possible Influence of Unknown Climate Forcings upon Global Temperature Increases from 1950-2000, J. Clim., 25, 7163-7172. doi:10.1175/JCLI-D-11-00645.1, 2012.

Bastidas, L. A., Hogue, T. S., Sorooshian, S., Gupta, H. V., and Shuttleworth, W. J.: Parameter sensitivity analysis for different complexity land surface models using multicriteria methods, J. Geophys. Res.-Atmos., 111, D20101, doi:10.1029/2005JD006377 2006.

Bauer, S. E., Wright, D. L., Koch, D., Lewis, E. R., McGraw, R., Chang, L.-S., Schwartz, S. E., and Ruedy, R.: MATRIX (Multiconfiguration Aerosol TRacker of mIXing state): an aerosol microphysical module for global atmospheric models, Atmos. Chem. Phys., 8, 6003-6035, doi:10.5194/acp-8-60032008, 2008.

Bond, T. C. and Bergstrom, R. W.: Light absorption by carbonaceous particles: An investigative review, Aerosol Sci. Technol., 40, 27-67, 2006.

Boucher, O. and Lohmann, U.: The sulfate-CCN-cloud albedo effect: A sensitivity study with two general circulation models, Tellus B, 47, 281-300, 1995.

Caflisch, R. E.: Monte Carlo and quasi-Monte Carlo methods, Acta Numerica, 7, 1-49, 1998.

Collins, W. D., Rasch, P. J., Boville, B. A., Hack, J. J., Mccaa, J. R., Williamson, D. L., and Briegleb, B. P.: The formulation and atmospheric simulation of the Community Atmosphere Model version 3 (CAM3), J. Clim., 19, 2144-2161, 2006.

Dentener, F., Kinne, S., Bond, T., Boucher, O., Cofala, J., Generoso, S., Ginoux, P., Gong, S., Hoelzemann, J. J., Ito, A., Marelli, L., Penner, J. E., Putaud, J.-P., Textor, C., Schulz, M., van der Werf, G. R., and Wilson, J.: Emissions of primary aerosol and precursor gases in the years 2000 and 1750 prescribed data-sets for AeroCom, Atmos. Chem. Phys., 6, 4321-4344, doi:10.5194/acp-64321-2006, 2006.

Dunion, J. P., and Velden, C. S.: The impact of the Saharan air layer on Atlantic tropical cyclone activity, B. Am. Meteorol. Soc., 85, 353-365, 2004.

Fast, J. D., Gustafson, Jr., W. I., Chapman, E. G., Easter, Jr., R. C., Rishel, J. P., Zaveri, R. A., Grell, G., and Barth, M.: The Aerosol Modeling Testbed: A community tool to objectively evaluate aerosol process modules, B. Am. Meteorol. Soc., 92, 343-360, doi:10.1175/2010BAMS2868.1, 2011.

Forster, P., Ramaswamy, V., Artaxo, P., Berntsen, T., Betts, R., Fahey, D. W., Haywood, J., Lean, J., Lowe, D. C., Myhre, G., Nganga, J., Prinn, R., Raga, G., Schulz, M., and Van Dorland, R.: Radiative Forcing of Climate Change, in Climate Change 2007:
The Physical Science Basis, Contribution of Working Group I to the Fourth Assessment Report of the Intergovernmental Panel on Climate Change, edited by: S. Solomon, D. Qin, M. Manning, Z. Chen, M. Marquis, K. B. Averyt, M. Tignor, and H. L. Miller, 129-234 pp., Cambridge Univ. Press, Cambridge, United Kingdom and New York, NY, USA, 2007.

Friedman, J. H.: Multivariate adaptive regression splines, Ann. Stat., 19, 1-141, 1991.

Gao, X. G., Sorooshian, S., and Gupta, H. V.: Sensitivity analysis of the biosphere-atmosphere transfer scheme, J. Geophys. Res.Atmos., 101, 7279-7289, 1996.

Gettelman, A., Morrison, H., and Ghan, S. J.: A new two-moment bulk stratiform cloud microphysics scheme in the Community Atmosphere Model, version 3 (CAM3) Part II: Single-column and global results, J. Clim., 21, 3660-3679, 2008.

Gettelman, A., Liu, X., Ghan, S. J., Morrison, H., Park, S., Conley, A. J., Klein, S. A., Boyle, J., Mitchell, D. L., and Li, J.-L. F.: Global simulations of ice nucleation and ice supersaturation with an improved cloud scheme in the Community Atmosphere Model, J. Geophys. Res., 115, D18216, doi:10.1029/2009JD013797, 2010.

Gettelman, A., Liu, X., Barahona, D., Lohmann, U., and Chen, C.: Climate Impacts of Ice Nucleation, J. Geophys. Res., 117, D20201, doi:10.1029/2012JD017950, 2012.

Ghan, S. J. and Easter, R. C.: Impact of cloud-borne aerosol representation on aerosol direct and indirect effects, Atmos. Chem. Phys., 6, 4163-4174, doi:10.5194/acp-6-4163-2006, 2006.

Ghan, S. J. and Zaveri, R. A.: Parameterization of Optical Properties for Hydrated Internally Mixed Aerosol, J. Geophys. Res., 112, D10201, doi:10.1029/2006JD007927, 2007.

Ghan S. J., Liu, X., Easter, Jr., R. C., Zaveri, R. A., Rasch, P. J., Yoon, J. H. and Eaton, B.: Toward a Minimal Representation of Aerosols in Climate Models: Comparative Decomposition of Aerosol Direct, Semidirect, and Indirect Radiative Forcing, J. Clim., 25, 6461-6476. doi:10.1175/JCLI-D-11-00650.1, 2012.

Golaz, J.-C., Salzmann, M., Donner, L. J., Horowitz, L. W., Ming, Y., and Zhao, M.: Sensitivity of the Aerosol Indirect Effect to Subgrid Variability in the Cloud Parameterization of the GFDL Atmosphere General Circulation Model AM3, J. Clim., 24, 3145-3160, 2011.

Haerter, J. O., Roeckner, E., Tomassini, L., and von Storch, J. S.: Parametric uncertainty effects on aerosol radiative forcing, Geophys. Res. Lett., 36, L15707, doi:10.1029/2009GL039050, 2009.

Hess, M., Koepke, P., and Schult, I.: Optical Properties of Aerosols and Clouds: The Software Package OPAC, B. Am. Meteorol. Soc., 79, 831-844, 1998.

Hoose, C., Kristjansson, J. E., Iversen, T., Kirkevag, A., Seland, Ø, and Gettelman, A.: Constraining cloud droplet number concentration in GCMs suppresses the aerosol indirect effect, Geophys. Res. Lett., 36, L12807, doi:10.1029/2009GL038568, 2009.

Hou, Z., Huang, M., Leung, L. R., Lin, G., and Ricciuto, D. M.: Sensitivity of surface flux simulations to hydrologic parameters based on an uncertainty quantification framework applied to the Community Land Model, J. Geophys. Res., 117, D15108, doi:10.1029/2012JD017521, 2012.

Hurrell, J., Holland, M., Ghan, S., Lamarque, J., Lawrence, D., Lipscomb, W., Mahowald, N., Marsh, D. R. , Neale, R. B., Rasch, P., Vavrus, S., Vertenstein M., Bader D., Collins, W. D. , Hack,J. J., Kiehl, J. , and Marshall, S.: The community earth system model: 
a framework for collaborative research, B. Am. Meteorol. Soc., 94, 1339-1360, doi:10.1175/BAMS-D-12-00121, 2013.

Iacono, M. J., Mlawer, E. J., Clough, S. A., and Morcrette, J.-J.: Impact of an improved longwave radiation model, RRTM, on the energy budget and thermodynamic properties of the NCAR community climate mode, CCM3, J. Geophys. Res., 105, 1487314890, 2000.

Jackson, C., Sen, M. K., and Stoffa, P. L.: An efficient stochastic Bayesian approach to optimal parameter and uncertainty estimation for climate model predictions, J. Climate, 17, 2828-2841, 2004.

Jackson, C. S., Sen, M. K., Huerta, G., Deng, Y., and Bowman, K. P.: Error reduction and convergence in climate prediction, J. Climate, 21, 6698-6709, doi:10.1175/2008jcli2112.1, 2008.

Kiehl, J. T.: Twentieth century climate model response and climate sensitivity, Geophys. Res. Lett., 34, L22710, doi:10.1029/ 2007GL031383, 2007.

Lamarque, J.-F., Bond, T. C., Eyring, V., Granier, C., Heil, A., Klimont, Z., Lee, D., Liousse, C., Mieville, A., Owen, B., Schultz, M. G., Shindell, D., Smith, S. J., Stehfest, E., Van Aardenne, J., Cooper, O. R., Kainuma, M., Mahowald, N., McConnell, J. R., Naik, V., Riahi, K., and van Vuuren, D. P.: Historical (1850-2000) gridded anthropogenic and biomass burning emissions of reactive gases and aerosols: methodology and application, Atmos. Chem. Phys., 10, 7017-7039, doi:10.5194/acp10-7017-2010, 2010.

Lee, L. A., Carslaw, K. S., Pringle, K. J., and Mann, G. W.: Mapping the uncertainty in global CCN using emulation, Atmos. Chem. Phys., 12, 9739-9751, doi:10.5194/acp-12-9739-2012, 2012.

Lee, L. A., Pringle, K. J., Reddington, C. L., Mann, G. W., Stier, P., Spracklen, D. V., Pierce, J. R., and Carslaw, K. S.: The magnitude and causes of uncertainty in global model simulations of cloud condensation nuclei, Atmos. Chem. Phys., 13, 8879-8914, doi:10.5194/acp-13-8879-2013, 2013.

Li, H., Huang, M., Wigmosta, M. S., Ke, Y., Coleman, A. M., Leung, L. R., Wang, A., and Ricciuto, D. M.: Evaluating runoff simulations from the Community Land Model 4.0 using observations from flux towers and a mountainous watershed, J. Geophys. Res.-Atmos., 116, D24120, doi:10.1029/2011JD016276 2011.

Liu, X., Penner, J. E., Ghan, S. J., and Wang, M.: Inclusion of ice microphysics in the NCAR Community Atmosphere Model version 3 (CAM3), J. Clim., 20, 4526-4547, 2007.

Liu, X., Xie, S., Boyle, J., Klein, S. A., Shi, X., Wang, Z., Lin, W., Ghan, S. J., Earle, M., Liu, P. S. K., Wang Z., and Zelenyuk, A.: Testing cloud microphysics parameterizations in NCAR CAM5 with ISDAC and M-PACE observations, J. Geophys. Res., 116, D00T11, doi:10.1029/2011JD015889, 2011.

Liu, X., Easter, R. C., Ghan, S. J., Zaveri, R., Rasch, P., Shi, X., Lamarque, J.-F., Gettelman, A., Morrison, H., Vitt, F., Conley, A., Park, S., Neale, R., Hannay, C., Ekman, A. M. L., Hess, P., Mahowald, N., Collins, W., Iacono, M. J., Bretherton, C. S., Flanner, M. G., and Mitchell, D.: Toward a minimal representation of aerosols in climate models: description and evaluation in the Community Atmosphere Model CAM5, Geosci. Model Dev., 5, 709-739, doi:10.5194/gmd-5-709-2012, 2012

Loeb, N. G., Wielicki, B. A., Doelling, D. R., Smith, G. L., Keyes, D. F., Kato, S., Manalo-Smith, N., and Wong, T.: Toward Optimal Closure of the Earth's Top-of-Atmosphere Radiation Budget, J. Clim., 22, 748-766, 2009.
Lohmann, U. and Feichter, J.: Global indirect aerosol effects: a review, Atmos. Chem. Phys., 5, 715-737, doi:10.5194/acp-5-7152005, 2005.

Lohmann, U., Quaas, J., Kinee, S., and Feichter, J.: Different approaches for constraining global climate models of the anthropogenic indirect aerosol effect, B. Am. Meteorol. Soc., 88, 243249, 2007.

Lohmann, U. and Ferrachat, S.: Impact of parametric uncertainties on the present-day climate and on the anthropogenic aerosol effect, Atmos. Chem. Phys., 10, 11373-11383, doi:10.5194/acp10-11373-2010, 2010.

McCullagh, P. and Nelder, J. A.: Generalized linear models, Chapman and Hall, 1989.

Mitchell, D. L.: Parameterization of the Mie extinction and absorption coefficients for water clouds, J. Atmos. Sci., 57, 1311-1326, 2000.

Mitchell, D. L., Baran, A. J., Arnott, W. P. and Schmitt, C.: Testing and comparing the modified anomalous diffraction approximation, J. Atmos. Sci., 63, 2948-2962, 2006.

Mitchell, D. L., Rasch, P., Ivanova, D., McFarquhar, G., and Nousiainen, T.: Impact of small ice crystal assumptions on ice sedimentation rates in cirrus clouds and GCM simulations, Geophys. Res. Lett., 35, L09806, doi:10.1029/2008GL033552, 2008.

Mlawer, E. J., Taubman, S. J., Brown, P. D., Iacono M. J., and Clough, S. A.: RRTM, a validated correlated-k model for the longwave, J. Geophys. Res., 102, 663-682, 1997.

Morris, M. D.: Factorial sampling plans for preliminary computational experiments, Technometrics, 33, 161-174, 1991.

Morrison, H. and Gettelman, A.: A New Two-Moment Bulk Stratiform Cloud Microphysics Scheme in the Community Atmosphere Model, Version 3 (CAM3). Part I: Description and Numerical Tests, J. Clim., 21, 3642-3659, doi:10.1175/2008JCLI2105.1, 2008.

Neale, R. B., Richter, J. H., and Jochum, M.: The impact of convection on ENSO: From a delayed oscillator to a series of events, J. Clim., 21, 5904-5924, 2008.

Neale, R. B., Richter, J. H., Conley, A. J., Park, S., Lauritzen, P. H., Gettelman, A., Williamson, D. L., Rasch, P. J., Vavrus, S. J., Taylor, M. A., Collins, W. D., Zhang, M., and Lin, S. J.: Description of the NCAR Community Atmosphere Model (CAM5.0), Technical Report NCAR/TN-486+STR, National Center for Atmospheric Research, Boulder, CO, USA, 2010.

Park, S. and Bretherton, C. S.: The University of Washington Shallow Convection and Moist Turbulence Schemes and Their Impact on Climate Simulations with the Community Atmosphere Model, J. Clim., 22, 3449-3469, doi:10.1175/2008JCLI2557.1, 2009.

Penner, J. E., Quaas, J., Storelvmo, T., Takemura, T., Boucher, O., Guo, H., Kirkevåg, A., Kristjánsson, J. E., and Seland, Ø.: Model intercomparison of indirect aerosol effects, Atmos. Chem. Phys., 6, 3391-3405, doi:10.5194/acp-6-3391-2006, 2006.

Quaas, J., Ming, Y., Menon, S., Takemura, T., Wang, M., Penner, J. E., Gettelman, A., Lohmann, U., Bellouin, N., Boucher, O., Sayer, A. M., Thomas, G. E., McComiskey, A., Feingold, G., Hoose, C., Kristjánsson, J. E., Liu, X., Balkanski, Y., Donner, L. J., Ginoux, P. A., Stier, P., Grandey, B., Feichter, J., Sednev, I., Bauer, S. E., Koch, D., Grainger, R. G., Kirkevåg, A., Iversen, T., Seland, Ø., Easter, R., Ghan, S. J., Rasch, P. J., Morrison, H., Lamarque, J.-F., Iacono, M. J., Kinne, S., and Schulz, M.: 
Aerosol indirect effects - general circulation model intercomparison and evaluation with satellite data, Atmos. Chem. Phys., 9, 8697-8717, doi:10.5194/acp-9-8697-2009, 2009.

Ramanathan, V. and Carmichael, G.: Global and regional climate changes due to black carbon, Nat. Geosci., 1, 221-227, 2008.

Rosero, E., Yang, Z.-L., Wagener, T., Gulden, L. E., Yatheendradas, S., and Niu, G.-Y.: Quantifying parameter sensitivity, interaction, and transferability in hydrologically enhanced versions of the Noah land surface model over transition zones during the warm season, J. Geophys. Res., 115, D03106, doi:10.1029/2009JD012035, 2010.

Saltelli, A. and Annonia, P.: How to avoid a perfunctory sensitivity analysis, Environ. Modell. Softw., 25, 1508-1517, 2010.

Sanderson, B. M., Piani, C., Ingram, W. J., Stone, D. A., and Allen, M. R.: Towards constraining climate sensitivity by linear analysis of feedback patterns in thousands of perturbed-physics GCM simulations, Clim. Dyn., 30, 175-190, 2008.

Schwartz, S. E.: Uncertainty requirements in radiative forcing of climate change, J. Air Waste Manage Assoc., 54, 1351-1359, 2004.

Sobol', I. M.: Sensitivity analysis for nonlinear mathematical models, Math. Mod. Comput. Exp., 1, 407-414, 1993.

Spracklen, D. V., Jimenez, J. L., Carslaw, K. S., Worsnop, D. R., Evans, M. J., Mann, G. W., Zhang, Q., Canagaratna, M. R., Allan, J., Coe, H., McFiggans, G., Rap, A., and Forster, P.: Aerosol mass spectrometer constraint on the global secondary organic aerosol budget, Atmos. Chem. Phys., 11, 12109-12136, doi:10.5194/acp-11-12109-2011, 2011.

Tarantola, A.: Inverse Problem Theory and Methods for Model Parameter Estimation, Society of Industrial and Applied Mathematics (SIAM), Philadelphia, PA, USA, 2005.

Textor, C., Schulz, M., Guibert, S., Kinne, S., Balkanski, Y., Bauer, S., Berntsen, T., Berglen, T., Boucher, O., Chin, M., Dentener, F., Diehl, T., Easter, R., Feichter, H., Fillmore, D., Ghan, S., Ginoux, P., Gong, S., Grini, A., Hendricks, J., Horowitz, L., Huang, P., Isaksen, I., Iversen, I., Kloster, S., Koch, D., Kirkevåg, A., Kristjansson, J. E., Krol, M., Lauer, A., Lamarque, J. F., Liu, X., Montanaro, V., Myhre, G., Penner, J., Pitari, G., Reddy, S., Seland, $\varnothing .$, Stier, P., Takemura, T., and Tie, X.: Analysis and quantification of the diversities of aerosol life cycles within AeroCom, Atmos. Chem. Phys., 6, 1777-1813, doi:10.5194/acp-6-1777-2006, 2006.
Venables, W. N. and Ripley, B. D.: Modern applied statistics with S, Springer, 2002.

Vignati, E., Facchini, M. C., Rinaldi, M., Scannell, C., Ceburnis, D., Sciare, J., Kanakidou, M., Myriokefalitakis, S., Dentener, F., and O'Dowd, C. D.: Global scale emission and distribution of seaspray aerosol: sea-salt and organic enrichment, Atmos. Environ., 44, 670-677, 2010.

Wang, H., Easter, R.-C., Rasch, P. J., Wang, M., Liu, X., Ghan, S.J., Qian, Y., Yoon, J.-H., Ma, P.-L., and Velu, V.: Sensitivity of remote aerosol distributions to representation of cloud-aerosol interactions in a global climate model, Geosci. Model Dev. Discuss., 6, 331-378, doi:10.5194/gmdd-6-331-2013, 2013.

Wang, X. Q. and Sloan, I. H.: Low discrepancy sequences in high dimensions: How well are their projections distributed? J. Comput. Appl. Math., 213, 366-386, 2008.

Yang, B., Qian, Y., Lin, G., Leung, R., and Zhang, Y.: Some issues in uncertainty quantification and parameter tuning: a case study of convective parameterization scheme in the WRF regional climate model, Atmos. Chem. Phys., 12, 2409-2427, doi:10.5194/acp-12-2409-2012, 2012.

Yang, B., Qian, Y., Lin, G., Leung, L. R., Rasch, P. J., Zhang, G. J., McFarlane, S. A., Zhao, C., Zhang, Y., Wang, H., Wang, M., and Liu, X.: Uncertainty quantification and parameter tuning in the CAM5 Zhang-McFarlane convection scheme and impact of improved convection on the global circulation and climate, J. Geophys. Res., 118, 395-415, doi:10.1029/2012JD018213, 2013.

Zhang, G. J. and McFarlane, N. A.: Sensitivity of climate simulations to the parameterization of cumulus convection in the Canadian Climate Centre general circulation model, Atmos. Ocean, 33, 407-446, 1995.

Zhao, C., Liu, X., Ruby Leung, L., and Hagos, S.: Radiative impact of mineral dust on monsoon precipitation variability over West Africa, Atmos. Chem. Phys., 11, 1879-1893, doi:10.5194/acp11-1879-2011, 2011.

Zhao, C., Leung, L. R., Easter, R., Hand, J., and Avise, J.: Characterization of speciated aerosol direct radiative forcing over California, J. Geophys. Res. Atmos., 118, 2372-2388, doi:10.1029/2012JD018364, 2013. 